\title{
Microphysics, Radiation and Surface Processes in the Goddard Cumulus Ensemble
} (GCE) Model

\author{
W.-K. Tao'1, J. Simpson1, D. Baker², S. Braun ${ }^{1}$, M.-D. Chou 1, B. Ferrier ${ }^{3}$, D. \\ Johnson 4 , A. Khain 5 , S. Lang6, B. Lynn ${ }^{5}$, C.-L. Shie ${ }^{4}$, C.-H. Sui ${ }^{1}$, X. Wang ${ }^{4}$ and \\ P. Wetzel ${ }^{1}$ \\ $1_{\text {Laboratory for Atmospheres }}$ \\ NASA/Goddard Space Flight Center \\ Greenbelt, MD 20771 \\ 2 Physics Department \\ Austin College \\ Sherman, TX 75090 \\ ${ }^{3}$ NCEP/Environmental Modeling Centers \\ Washington, D. C. 20233

 \\ University of Maryland, Baltimore County \\ Baltimore, $M D$ \\ 5 Department of Atmospheric Science \\ Hebrew University of Jerusalem \\ Jerusalem, Israel \\ 6Science Systems and Applications Inc. \\ NASA/Goddard Space Flight Center \\ Greenbelt, MD 20771 \\ Special Issue \\ on \\ "Nonhydrostatic Meso-scale Modelling" \\ Meteorology and Atmospheric Physics
}

(February 21, 2001)

Corresponding author address: Dr. Wei-Kuo Tao, Mesoscale Atmospheric Processes Branch, Code 912, NASA/GSFC, Greenbelt, MD 20771

email: tao@agnes.gsfc.nasa.gov 


\begin{abstract}
The response of cloud systems to their environment is an important link in a chain of processes responsible for monsoons, frontal depression, El NinoSouthern Oscillation (ENSO) episodes and other climate variations (e.g., 30-60 day intra-seasonal oscillations). Numerical models of cloud properties provide essential insights into the interactions of clouds with each other, with their surroundings, and with land and ocean surfaces. Significant advances are currently being made in the modeling of rainfall and rain-related cloud processes, ranging in scales from the very small up to the simulation of an extensive population of raining cumulus clouds in a tropical- or midlatitude-storm environment.
\end{abstract}

The Goddard Cumulus Ensemble (GCE) model is a multi-dimensional nonhydrostatic dynamic/microphysical cloud resolving model. It has been used to simulate many different mesoscale convective systems that occurred in various geographic locations. In this paper, recent GCE model improvements (microphysics, radiation and surface processes) will be described as well as their impact on the development of precipitation events from various geographic locations. The performance of these new physical processes will be examined by comparing the model results with observations. In addition, the explicit interactive processes between cloud, radiation and surface processes will be discussed. 


\section{Introduction}

The role of clouds/cloud systems in global energy and hydrological balance is very complex. Clouds owe their origin to large-scale dynamic and thermodynamic forcing (disturbances), radiative cooling in the atmosphere, and turbulent transfer processes at the surface (e.g., the transfer of heat and moisture from the ocean to the atmosphere). Latent heat release in precipitating clouds provides three-fourths of the energy received by the atmosphere. Clouds serve as important mechanisms for the vertical redistribution of momentum, trace gases (including the Greenhouse gas $\mathrm{CO}_{2}$ ), and sensible and latent heat on the large-scale. They also influence the coupling between the atmosphere and the earth's surface as well as the radiative and dynamical-hydrological balances. The vertical distribution of convective latent-heat release can modulate the large-scale circulations of the tropics (e.g., the 30-60 day intraseasonal oscillation) and their impact upon midlatitude weather through teleconnection patterns such as El Niño.

How large-scale disturbances control the evolution of convective systems, ensembles and convective cells, and the impact (or feedback) of these cloud systems (including their interaction with radiation) on the large-scale disturbances are two of the most challenging problems in atmospheric science. Furthermore, changes in the moisture distribution at middle and upper levels of the troposphere as well as the radiative responses of cloud hydrometeors to outgoing longwave and incoming shortwave radiation are a major factor in determining whether the earth system will warm or cool as the cloud systems respond to changes in their environment (Ramanathan et al. 1989; Lindzen 1990a, b; Betts 1990; Lau et al. 1993). At present, one of the major limitations of global modeling still resides in the representation of clouds (latent heat release) and their interactions with the radiation balance both locally and on the global scale ${ }^{1}$.

A basic characteristic of the cloud resolving models (CRMs) is that their governing equations are non-hydrostatic since the vertical and horizontal scales of convection are similar. Such models are also necessary in order to allow gravity waves, such as those triggered by clouds, to be resolved explicitly. The cloud

1 The highest science priority identified in the Global Change Research Program (GCRP) is the role of clouds in climate and hydrological systems, which have been identified as being the most problematic issues facing global change studies. 
resolving models use more sophisticated and physically realistic parameterizations of cloud microphysical processes with very fine spatial and temporal resolution. Another major characteristic of the cloud resolving models is an explicit interaction between clouds and radiation. It is for this reason that GEWEX (Global Energy and Water Cycle Experiment) has formed the GCSS (GEWEX Cloud System Study) expressly for the purpose of studying these types of problems using CRMs. Observations can be used to verify model results and improve the initial and boundary conditions. The major advantages of using cloud resolving models are their ability to quantify the effects of each physical process upon convective events by means of sensitivity tests (eliminating a specific process such as evaporative cooling, terrian, PBL), and their detailed dynamic and thermodynamic budget calculations.

The Goddard Cumulus Ensemble (GCE) model is a cloud resolving model, and its main features have been previously published by Tao and Simpson (1993) and Simpson and Tao (1993). Since then, the GCE model has been significantly improved. Specifically, there are five major improvements, namely, microphysics, radiative transfer processes, land surface processes, ocean surface processes and ocean mixed layer processes. In this paper, these improvements and their impact on simulating different mesoscale convective systems in various geographic locations will be presented.

\section{Goddard Cumulus Ensemble (GCE) Model}

The GCE model variables include horizontal and vertical velocities, potential temperature, perturbation pressure, turbulent kinetic energy, and mixing ratios of all water phases (vapor, liquid, and ice). Novel characteristics of the GCE model are the explicit representation of warm rain and ice microphysical processes, and their complex interactions with solar and infrared radiative transfer processes, and with surface processes. The GCE model is being linked with other physical models such as: passive microwave radiative transfer and spaceborne precipitation radar models for the purposes of developing and improving retrieval algorithms of precipitation and latent heat release, and a photo-chemistry model to assess the impact of vertical transport and mixing of important trace species on $\mathrm{O}_{3}$ production/reduction processes. Figure 1 shows schematically the GCE model's major characteristics. 
The equations which govern cloud scale motion in the GCE model are either anelastic or compressible. For the anelsatic system, sound waves are filtering out by neglecting the local variation of air density with time in the mass equation. The GCE model can be run either two or three dimensional. The lateral boundary conditions can be chosen to be cyclic, open or mixed (cyclic in one lateral boundary and open in another). Also, an axis-symmetric version of the model is available to study the physical processes associated with hurricanes.

The use of GCE model to study convection can generally be categorized into two groups. The first approach is so-called "cloud ensemble modeling" (Tao 1978; Soong and Ogura 1980; Soong and Tao 1980; Tao and Soong 1986; and many others). In this approach, many clouds of different sizes in various stages of their lifecycles can be present at any model simulation time. The large-scale effects (forcing) are always applied to the model continuously. These are derived from observations such as convergence in the wind field. The cyclic lateral boundary conditions (to avoid reflection of gravity waves) and a large horizontal domain (to allow for the existence of an ensemble of clouds) are required. The clouds simulated from this approach could be termed "continuous large-scale forced convection" or "continuously forced convection". On the other hand, the second type of GCE modeling does not require large-scale effects to initialize and maintain cloud development. This type of simulation requires initial temperature and water vapor profiles which have a medium to large convective available potential energy (CAPE), and an open lateral boundary condition is always used (Tao $e t$ al. 1991, 1993, 1996; Ferrier et al. 1995; Wang et al. 1996; 2001; and many others). The modeled clouds are then initialized with either a cool pool, warm bubble or surface processes (i.e., land/ocean fluxes). These modeled clouds could be termed "self-forced convection"; they are mainly for case study (i.e., for 6-12 h time integration).

A second- or fourth-order horizontal advection scheme has generally been used in the model. However, using second-order or higher-order accuracy advection schemes can introduce some difficulties because negative values arise in the solution (Soong and Ogura 1973). This effect can be especially important in cases where the solution of the advection is used as input to nonlinear equations describing microphysical phenomena or inert tracers which can eventually lead to 
instability of the whole system (Smolarkiewicz 1983). The use of upstream differencing or other low-order schemes (Soong and Ogura 1973) would not produce dispersive "ripples" but would suffer from excessive numerical diffusion. Smolarkiewicz (1983) has reduced the implicit diffusion by using a second "upstream" step where a specifically defined velocity field leads to a new form of a positive definite advection scheme with small implicit diffusion. The positive definite advection scheme involves iterations and needs more computational resources. This scheme has been improved to include multidimensional applications (Smolarkiewicz 1984) and a non-oscillatory option (Smolarkiewicz and Grabowski 1990). Recently, the GCE model has implemented this Multidimensional Positive Definite Advection Transport Algorithm (MPDATA). All scalar variables (potential temperature, water vapor, turbulent coefficient and all five hydrometeor classes) use forward time differencing and the MPDATA for advection. The dynamic variables, $u, v$ and $w$, use a second-order accurate advection scheme and a leapfrog time integration (kinetic energy semi-conserving method). The impact of advection schemes on organization and precipitation processes associated with tropical and midlatitude squall lines is quantified by Lang et al. (2001).

A stretched vertical coordinate (height increments from 20 to $1150 \mathrm{~m}$ ) is used to maximize resolution in the lowest levels of the model. Typically, a total of 1024 grid points are used in the horizontal with $50-1000 \mathrm{~m}$ resolution in the twodimensional version of the GCE model. In the three-dimensional version of the GCE model, the horizontal resolution is usually $1000-2000 \mathrm{~m}$ with 200 by 200 grid points. The time step is 5 to $10 \mathrm{~s}$.

In the past two decades, the applications of the GCE model to the study of precipitation processes can be generalized into fourteen categories (see Table 1). It has been used to provide essential insights into the interactions of clouds with each other (Tao and Simpson 1984, 1989a), with their surroundings, and their associated heat, moisture, momentum, mass and water budgets (Tao 1978; Soong and Tao 1980, 1984; Tao and Soong 1986; Tao, Simpson and Soong 1987; Tao and Simpson 1989b), with radiative transfer processes (Tao et al. 1991, 1993a, 1996; Sui et al. 1998), with ocean surfaces (Tao et al. 1991; Wang et al. 1996, 2001), with idealized climate variations [Lau et al. 1993, 1994; Sui et al. 1994; Tao et al. 1999, 2001(b)], and cloud draft structure and trace gas transport (Scala et al. 1990; 
Pickering et al. 1992; and a review by Thompson et al. 1997) and precipitation efficiency (Ferrier et al. 1996). The GCE model has also been used to convert the radiances received by cloud-observing microwave radiometers into predicted rainfall rates (Simpson et al. 1988, and a review by Simpson et al. 1996). Remote sensing of cloud-top properties by high-flying aircraft bearing microwave and other instruments is now beginning to provide powerful tests of the GCE model, particularly when such observations are augmented by simultaneous groundbased radar measurements (Adler et al. 1991; Prasad et al. 1995; Yeh et al. 1995). The GCE model has also been used to study the distribution of rainfall and inferred heating [Tao et al. 1990, 1993b, 2000 and 2001(a)].

\section{GCE Model Major Improvements}

\subsection{Goddard Microphysics}

Table 2 shows the microphysical schemes that were implemented (coded) and tested in the GCE model. McCumber et al. (1991) have tested the impact of warm rain only (no ice), two class ice and two different three-class ice schemes on the development and organization of a GATE squall line. In this paper, only newer improvements (three class ice schemes, four class ice scheme, and spectral bin microphysics) will be addressed.

\section{(a) Three Class Ice (3ICE) Scheme}

A two-class liquid and three-class ice microphysics scheme (Fig. 2) developed and coded at Goddard (Tao and Simpson 1993) was mainly based on Lin et al. (1983) with additional processes from Rutledge and Hobbs (1984). However, the Goddard microphysics scheme has several modifications. The modifications include: (1) the option to choose either graupel or hail as the third class of ice (McCumber et al. 1991). Graupel has a low density and a large intercept (i.e., high number concentration). In contrast, hail has a high density and a small intercept (low number concentration). These differences can affect not only the description of the hydrometeor population, but also the relative importance of the microphysicaldynamical-radiative processes. (2) the saturation technique (Tao et al. 1989): This saturation technique is basically designed to ensure that supersaturation (subsaturation) cannot exist at a grid point that is clear (cloudy). This saturation 
technique is one of the last microphysical processes to be computed. It is only done prior to evaluating evaporation of rain and snow/graupel/hail deposition or sublimation. (3) Another difference is that all microphysical processes (transfer rates from one type of hydrometeor to another) that do not involve melting, evaporaion and sublimation, are calculated based on one thermodynamic state. This ensures that all these processes are treated equally. The opposite approach is to have one particular process calculated first modifing the temperature and water vapor content (i.e., through latent heat release) before the second process is computed.

Recently, Scott et al. (2001) modified the conversion of cloud ice to snow in the 3ICE schemes. Various assumptions associated with saturation technique were also revisited and examined. These modifications and their impacts on precipitation processes will be presented and discussed in later sections.

\section{(b) Two Moments Four Class Ice (4ICE) Scheme}

An improved microphysical parameterization called 4ICE has been developed and implemented into the two-dimensional version of the GCE model (Ferrier 1994; Ferrier et al. 1995), which combines the main features of previous three-class ice schemes by calculating the mixing ratios of both graupel and frozen drops/hail. Additional model variables include the number concentrations of all ice particles (small ice crystals, snow, graupel and frozen drops), as well as the mixing ratios of liquid water in each of the precipitation ice species during wet growth and melting for purposes of accurate active and passive radiometric calculations. The scheme also includes the following: (1) more accurate calculation of accretion processes, including partitioning the freezing of raindrops as sources of snow, graupel and frozen drops/hail; (2) consideration of rime densities and riming rates in converting between ice species due to rapid cloud water riming; (3) incorporation of new parameterizations of ice nucleation processes, the rime splintering mechanism using laboratory data, and the aircraft observations of high ice particle concentrations; (4) shedding of liquid water from melting ice and from excessive amounts of water accumulated on supercooled frozen drops/hail; (5) preventing unrealistically large glaciation rates immediately above the freezing level by explicitly calculating freezing rates of raindrops and freezing rates of liquid water accreted onto supercooled ice; (6) introducing fall speeds and size distributions for 
small ice crystals; (7) calculating radar reflectivities of particles with variable size distributions and liquid water coatings from Rayleigh theory; (8) basing conversion of particle number concentrations between hydrometeor species on preserving spectral characteristics of particle distributions rather than conserving their number concentrations (important). A detailed description of these parameterized processes can be found in Ferrier (1994). Table 3 shows the major differences between the 3 and 4 class ice scheme.

The 4ICE scheme was recently coupled with the MPDATA, substantially reducing the decoupling of mixing ratios and number concentrations caused by advection errors, resulting in a significant improvement in model performance (discussed in results section). The 4ICE scheme was also implemented into the three-dimensional version of the GCE model. The impact of the 3ICE or 4ICE scheme on the organization of two tropical squall systems will be presented in a later section.

\section{(c) Spectral-Bin Microphysics}

The formulation of the explicit spectral bin-microphysical processes is based on solving stochastic kinetic equations for the size distribution functions of water droplets (cloud droplets and raindrops), and six types of ice particles: pristine ice crystals (columnar and plate-like), snow (dendrites and aggregates), graupel and frozen drops/hail. Each type is described by a special size distribution function containing 43 categories (bins). Atmospheric aerosols are also described using number density size-distribution functions. This model is specially designed to take into account the effect of atmospheric aerosols on cloud development and precipitation formation. Droplet nucleation (activation) is derived from the analytical calculation of supersaturation, which is used to determine the sizes of aerosol particles to be activated and the corresponding sizes of nucleated droplets. Primary nucleation of each type of ice crystal takes place within certain temperature ranges. The rate of primary ice generation and freezing is calculated using a semi-lagrangian approach allowing one to calculate changes in supersaturation and temperature in moving cloud parcels attaining model grid points (Khain et al. 2000). Secondary ice generation is described by the Halett and Mossop (1974) mechanism, where, for every 250 collisions between droplets with radii exceeding $20 \mu \mathrm{m}$ and graupel particles, one ice splinter is formed. Based on 
measurements, this process is assumed to occur within the -3 to $-8{ }^{\circ} \mathrm{C}$ temperature range. The rate of drop freezing follows the observations of immersion nuclei by Vali (1975) and homogeneous freezing by Pruppacher (1995). Diffusion growth of water droplets and ice particles is calculated from analytical solutions for supersaturation with respect to water and ice. The shape of the ice crystals is accounted for in the calculation of diffusion growth for the different ice crystals. An efficient and precise method of solving the stochastic kinetic equation (Bott 1998) was extended to a system of stochastic kinetic equations calculating waterwater, water-ice and ice-ice collisions. The model uses height-dependent dropdrop and drop-graupel collision kernels calculated from a hydrodynamic method valid within a wide range of drop and graupel sizes (Khain et al. 1999b; Pinsky et al. 2000b). Ice-water and ice-ice collision kernels are calculated taking into account the shapes of the ice crystals and the dispersion of terminal velocities for crystals of the same mass but different shape. Ice-ice collision rates are assumed to be temperature dependent. An increase in the water-water and water-ice collision kernels by the turbulent/inertia mechanism was taken into account following Khain and Pinsky (1997), Pinsky and Khain (1998) and Pinsky et al. (1998, 1999, 2000a). The model provides precipitation rates, accumulated rain, mass contents, total water and ice radar reflectivities, and mean and effective radii of droplets and ice particles. A detailed description of these explicitly parameterized processes can be found in Khain and Sednev (1996) and Khain et al. (1999a, 2000). Table 4 shows the physical processes represented in the spectral bin-microphysical scheme. The interactions assumed between water drops and ice particles and between ice particles, as well as the results of these interactions, are shown in Table 5.

The GCE explicit spectral bin microphysics can be used to study cloudaerosol interactions and nucleation scavenging of aerosols, as well as the impact of different concentrations and size distributions of aerosol particles upon cloud formation. The spectral bin microphysics is expected to lead to a better understanding of the mechanisms that determine the intensity and the formation of precipitation for a wide spectrum of atmospheric phenomenon related to clouds. In addition, the spectral bin microphysics can be used to improve the simpler bulk (3ICE and 4ICE) parameterizations. The sensitivity of cloud development and surface rainfall to dirty (high number concentration of aerosols) or clean (low number concentration of aerosols) air environments for an idealized case will be presented. 


\subsection{Goddard Radiation Scheme}

The interaction between clouds and radiation is two-way. On the one hand, clouds can reflect incoming solar and outgoing long-wave radiation. On the other hand, radiation can enhance or reduce the cloud activity. See Tao et al. (1996) for a review on studying the cloud-radiation interactions using the cloud resolving models.

\section{(a) Radiative Transfer Processes}

The radiative transfer package developed by Chou $(1984,1986)$ and Chou and Kouvaris (1991) has been implemented into the GCE model. This radiation scheme is a broad-band model and is considered state-of-the-art in the General Circulation Modeling community (the UCLA GCM, Goddard GCM, CSU GCM and FSU global model have all adopted this radiative scheme). The solar radiation parameterization is documented in Chou and Suarez (1999). It includes absorption due to water vapor, $\mathrm{CO}_{2}, \mathrm{O}_{3}$, and $\mathrm{O}_{2}$. Interactions among the gaseous absorption and scattering by clouds, aerosols, molecules (Rayleigh scattering), and the surface are fully taken into account. Fluxes are integrated virtually over the entire spectrum, from $0.175 \mu \mathrm{m}$ to $10 \mu \mathrm{m}$. The spectrum is divided into seven bands in the ultraviolet (UV) region $(0.175-0.4 \mu \mathrm{m})$, one band in the photosynthetically active radiation (PAR) region $(0.4-0.7 \mu \mathrm{m})$, and three bands in the near infrared region $(0.7-0.10 \mu \mathrm{m})$. In the $\mathrm{UV}$ and PAR region, a single $\mathrm{O}_{3}$ absorption coefficient and a Rayleigh scattering coefficient are used for each of the eight bands. The $\mathrm{O}_{3}$ absorption coefficient is taken from the spectral values given in WMO (1985). In the infrared, the k-distribution method is applied to compute the absorption of solar radiation. Ten $k$-distribution functions (equivalently, ten $k$ values) are used in each of the three bands. The one-parameter scaling is used to compute the absorption coefficient in individual layers where temperature and pressure vary with height. The absorption due to $\mathrm{O}_{2}$ is derived from a simple function, and the absorption due to $\mathrm{CO}_{2}$ is derived from precomputed tables. Reflection and transmission of a cloud and aerosol-laden layer are computed using the $d$ Eddington approximation. Fluxes for a composite of layers are then computed using the two-stream adding approximation. 
Various components of the thermal-infrared radiation parameterizations are given in Chou and Suarez (1994), Kratz et al. (1998), Chou et al. (1998), and Chou et al. (1999). The spectrum is divided into nine bands. As in the solar spectral region, the k-distribution method with temperature and pressure scaling is used to compute the transmission function in the weak absorption bands of water vapor and minor trace gases $\left(\mathrm{N}_{2} \mathrm{O}, \mathrm{CH}_{4}, C F C^{\prime} \mathrm{s}\right)$. Six values of $\mathrm{k}$ are used for water vapor absorption, and only a few values of $\mathrm{k}$ are used for the minor trace gases. For the strong absorption bands of water vapor, the $15-\mu \mathrm{m} \mathrm{CO}_{2}$ band, and the 9.6- $\mathrm{m} \mathrm{O}_{3}$ band, the cooling is strong in the upper stratosphere. The use of the k-distribution method with the one-parameter temperature and pressure scaling induces a large error in the cooling rate above the $20-\mathrm{mb}$ level. Instead, a look-up table method is used to compute the transmission function in the strong absorption bands, which computes accurately the cooling rate from the surface to the $0.01-\mathrm{mb}$ level.

\section{(b) Cloud Optical Properties}

Using a fully explicit microphysics scheme (liquid and ice) and a fine horizontal resolution ( $5 \mathrm{~km}$ or less) can give realistic cloud optical properties, which are crucial for determining the radiation budgets, with less tuning though it is still not perfect. Each model grid is considered either completely cloudy or clear. No partial cloudiness is assumed.

The effect of clouds on the scattering of thermal infrared radiation (IR) is small but cannot be neglected. To avoid expensive computations, the effect of scattering by clouds is included in transmission calculations by scaling the optical thickness without explicitly computing the scattering of infrared radiation by clouds. Thus, the optical thickness is scaled by

$$
\tau^{\prime}=(1-\omega f) \tau
$$

where $f$ is the fraction of radiation scatter forward and is a simple function of $g$. For a spectral band, the optical thickness, single-scattering albedo, $\omega$, and asymmetry factor,gare given by

$$
\tau=W\left(a_{o}+a_{1} / r_{e}{ }^{a_{2}}\right)
$$




$$
\begin{aligned}
& 1-\omega=\sum_{n=o}^{4} b_{n} r_{e}^{n} \\
& g=\sum_{n=o}^{4} c_{n} r_{e}^{n}
\end{aligned}
$$

where $a_{n}, b_{n}$, and $c_{n}$ are regression coefficients. $W$ is the the cloud water/ice amount, and the effective particle size, $r_{e}$, is defined to be proportional to the ratio of the total volume of cloud particles to the total cross-sectional area of cloud particles. For water droplets, these regression coefficients are derived based on the spectral optical properties calculated from Mie theory. For ice crystals, they are derived using the spectral optical data of Fu et al. (1998), which employs a linear combination of single-scattering properties derived from Mie theory, anomalous diffraction theory, and the geometric optics method.

For solar radiation, the optical thickness of cloud layer, $\tau$, is parameterized as a function of the cloud water/ice amount, $W$, and the effective particle size, $r_{e}$, whereas the single-scattering albedo, $\omega$, and asymmetry factor, $g$, are parameterized as a function of $r_{e}$,

$$
\begin{aligned}
& \tau=W\left(a_{o}+a_{1} / r_{e}\right) \\
& 1-\omega=\sum_{n=o}^{3} b_{n} r_{e}^{n} \\
& g=\sum_{n=o}^{3} c_{n} r_{e}^{n}
\end{aligned}
$$

where $a_{n}, b_{n}$, and $c_{n}$ are regression coefficients. The spectral single-scattering properties of ice crystals calculated by $\mathrm{Fu}(1996)$ are used to derive the regression coefficients. The spectral single-scattering properties of cloud droplets are computed using Mie theory. For raindrops, the optical properties computed by Fu et al. (1995) are used to derive the regression coefficients. The parameterizations are applied separately to water and ice particles.

There is a second method (or option) for calculating the cloud optical depth $(\tau)$ and effective particle size (or radius $r_{e}$ ) in the GCE model. This cloud optical parameterization scheme is based on Sui et al. (1995) following Fu and Liou (1993) and Platt and Harshrardhan (1988). The optical depth of large precipitating 
particles (rain) is based on the commonly used broad-band emissivity method [see Stephens $(1978,1984)]$. The optical depth $(\tau)$ of rain is parameterized as

$$
\tau=\frac{3}{2} \frac{W_{1}}{r_{e}}
$$

where $W_{1}$ liquid/ice water path $\left(\mathrm{g} \mathrm{m}^{-2}\right)$ and $r_{e}$ the effective radius (micrometers) are defined as follows:

$$
\begin{aligned}
& \mathrm{r}_{\mathrm{e}}=\frac{\int_{0}^{\infty} \mathrm{N}(\mathrm{r}) \mathrm{r}^{3} \mathrm{dr}}{\int_{0}^{\infty} \mathrm{N}(\mathrm{r}) \mathrm{r}^{2} \mathrm{dr}} \\
& \mathrm{W}_{\mathrm{l}}=\int_{0}^{\Delta \xi} \mathrm{w}_{1} \mathrm{dz}
\end{aligned}
$$

where $w_{1}$ is the liquid or ice water content $\left(\mathrm{g} \mathrm{m}^{-3}\right)$.

In the water phase, the optical depth of rain for solar radiative heating $\left(\tau_{\mathrm{SW}}\right)$ is parameterized following (8). However, the optical depth of cloud for longwave radiative calculations $\left(\tau_{\mathrm{IR}}\right)$ is assumed to be half of $\tau_{\mathrm{SW}}$. For cloud ice and snow, the optical depth is parameterized using the relations:

$$
\begin{aligned}
& \tau_{\mathrm{SW}}=\left(-0.006656+3.686 * 10^{-4} / \mathrm{D}_{\mathrm{c}}\right) * \mathrm{~W}_{\mathrm{l}} \\
& \tau_{\mathrm{IR}}=\left(-0.0115+4.11 * 10^{-4} / \mathrm{D}_{\mathrm{e}}+17.3 \times 10^{-8} / \mathrm{D}_{\mathrm{e}}{ }^{2}\right) * \mathrm{~W}_{\mathrm{I}}
\end{aligned}
$$

where $D_{c}$ is the mean effective size of ice crystals and is assumed to be a function of temperature as:

$$
\mathrm{D}_{\mathrm{e}}=0.0125 \mathrm{~cm}+\left(\mathrm{T}+30^{\circ} \mathrm{C}\right) * 0.00050-30^{\circ} \mathrm{C}>\mathrm{T}>-50^{\circ} \mathrm{C}
$$

For temperatures colder than $-50{ }^{\circ} \mathrm{C}$ or warmer than $-30^{\circ} \mathrm{C}, \mathrm{D}_{\mathrm{e}}$ is $25 \mu \mathrm{m}$ and $125 \mu \mathrm{m}$, respectively. The optical depth and effective radius of graupel/hail, however, is parameterized as those of (8) and (9). The effective radius of cloud water is specified to be $0.0003 \mathrm{~cm}$ (Wong et al. 1993).

Predicted radiative cooling and heating rates at cloud-top from both methods are on the order of 30 to $50 \mathrm{~K} /$ day, which is in good agreement with Ackerman et 
al. (1988) and Stephens (1978). Sensitivity tests have been performed to examine the impact of various cloud optical property calculations on the rainfall. The results show that the impact of various cloud optical property calculations is greater in tropical cases, $3-5 \%$ compared to $1-2 \%$ for their midlatitude counterparts.

\subsection{Goddard Land Processes (PLACE)}

The land and atmosphere form a highly coupled system. The surface convective fluxes are coupled to the surface net radiation flux, the vegetation state, and the profiles of temperature and water, below the surface and up through the atmospheric planetary boundary layer. These processes at the land-atmosphere interface are influenced in a fundamental way by topographic features and the heterogeneous character of the land surface layer. The fluxes of heat and moisture across the interface vary on spatial scales ranging from meters to thousands of kilometers. Modeling these coupled surface-atmospheric processes is crucial to the understanding and simulation of climate system interactions. The GCE model has recently implemented a detailed soil-vegetation land model to study precipitation processes that involve the interaction between land and atmosphere.

The PLACE model (Parameterization for Land-Atmosphere Cloud Exchange, Fig. 3) is a detailed interactive process model of the heterogeneous land surface (soil and vegetation) and adjacent near-surface atmosphere. PLACE basically consists of three elements. These are: (1) a soil module that includes at least seven water reservoirs (i.e. plant internal storage, dew/intercepted precipitation, surface material (no roots), a topsoil root layer, a subsoil root layer, and two deeper layers that regulate seasonal and interannual variability of the soil hydrology); (2) a surface slab of vegetation, litter and other loose material which shades the soil and acts as the source for sensible heat flux, and which intercepts precipitation and dew; and (3) the surface layer of the atmosphere (up to the lowest computational level of the model to which it is coupled) within which the fluxes of sensible heat and water vapor are calculated. More details on PLACE can be found in Wetzel and Boone (1995). PLACE has been a very active participant in two major international intercomparison projects, sponsored by WCRP/GEWEX: The Project for the Intercomparison of Land surface Parameterization Schemes (PILPS, see Henderson-Sellers et al. 1993, 1995) and the Global Soil Wetness Project (GSWP, see Boone and Wetzel 1999). This work has demonstrated that PLACE is 
as accurate as other widely used GCM parameterizations, such as BATS. However PLACE has been specifically designed to be applied to mesoscale models with grid resolutions of $100 \mathrm{~km}$ or smaller. PLACE was linked to the GCE model to study the impact of soil moisture patches and atmospheric boundary conditions on cloud structure, rainfall, and soil moisture distribution [Lynn et al. 1998, 2001(a)], to investigate the impact of coastline curvature and initial land breeze on intensity of surface precipitation associated with Florida mesoscale convective systems (Baker et al. 2001) and to parameterize the triggering associated with landscapes-generated mesoscale circulations (Lynn and Tao 2001).

\subsection{TOGA COARE Flux Algorithm}

Surface fluxes are temporally and spatially complex in the region of active convection. Observational studies in the western Pacific warm pool region (Bradley et al. 1991; Young et al. 1992; Fairall et al. 1996) have shown that surface heat and momentum fluxes all have a peak in the convective leading edge due to strong gust winds and colder air temperatures in the convective region. The surface fluxes in the large clear area are much smaller and more uniform than those in the convective region. Several numerical modeling studies (i.e., Tao et al. 1991; Wang et al. 1996) have indicated that sensible and latent heat fluxes can enhance surface precipitation and cloud coverage by comparing simulations with and without the effects of ocean fluxes for both subtropical and tropical squall lines.

The surface flux parameterization used in the GCE model is from the TOGA COARE flux algorithm (Fairall et al. 1996). This parameterization is primarily based on the bulk scheme developed by Liu et al. (1979), which has shown good agreement with observations (Bradley et al. 1991). The transfer coefficients for momentum, sensible heat, and latent heat fluxes are based on the MoninObukhov similarity theory of the atmospheric surface layer (Businger et al. 1971). This bulk scheme has been modified (Fairall et al. 1995; Bradley et al. 1991) to accommodate very low surface wind situations. The TOGA COARE flux algorithm is derived from data sets of TOGA COARE observations and is, perhaps, more accurate for the simulation of of the surface fluxes in the tropical convective environment. 
According to the Monin-Obukhov similarity theory, the mean profiles of wind speed, potential temperature, and moisture have the following relations (Businger 1973):

$$
\begin{aligned}
& \left(U-U_{s}\right) / u_{*}=\left[\ln \left(z / z_{M}\right)-\Psi_{M}(\zeta)\right] / k_{M} \\
& \left(\theta-\theta_{s}\right) / \theta_{*}=\left[\ln \left(z / z_{H}\right)-\Psi_{H}(\zeta)\right] / k_{H} \\
& \left(q-q_{s}\right) / q_{*}=\left[\ln \left(z / z_{E}\right)-\Psi_{E}(\zeta)\right] / k_{E}
\end{aligned}
$$

where $u^{*}$ is the friction velocity, $\theta_{*}$ is the temperature scaling parameter, and $q_{*}$ is the moisture scaling parameter. $k_{M}, k_{H}$ and $k_{E}$ are the Von Karman constants. $z_{M}, z_{H}$ and $z E$ are the roughness lengths. $\Psi_{M}, \Psi_{H}, \Psi_{E}$ are the stability functions of $\zeta$ which is equal to $z / L$ (where $L$ is the Monin-Obukhov length). The subscript $s$ represents those variables at the ocean surface and the subscripts $M, H$ and $E$ represent the parameters associated with momentum, sensible heat, and latent heat, respectively. The momentum, sensible heat and latent heat fluxes can be expressed as:

$$
\begin{aligned}
& -\overline{u^{\prime} w^{\prime}}=C_{M} U^{2}=u_{*}^{2} \\
& \overline{w^{\prime} \theta^{\prime}}=C_{H} U\left(\theta-\theta_{s}\right)=-u_{*} \theta_{*} \\
& \overline{w^{\prime} q^{\prime}}=C_{E} U\left(q-q_{s}\right)=-u_{*} q_{*}
\end{aligned}
$$

where $C_{M}, C_{H}$ and $C_{E}$ are the transfer coefficients for momentum, sensible heat, and latent heat. These bulk coefficients are related to the similarity profiles (15) as:

$$
\begin{aligned}
& C_{M}=k_{M}^{2} /\left[\ln \left(z / z_{M}\right)-\Psi_{M}(\zeta)\right]^{2} \\
& C_{H}=C_{M}^{1 / 2} k_{H} /\left[\ln \left(z / z_{H}\right)-\Psi_{H}(\zeta)\right] \\
& C_{E}=C_{M}^{1 / 2} k_{E} /\left[\ln \left(z / z_{E}\right)-\Psi_{E}(\zeta)\right]
\end{aligned}
$$

The parameters, such as the roughness lengths, are closely related to the sea surface characteristics and the turbulence characteristics. In very low wind speed conditions, the similarity profile (15) becomes singular. This singularity was effectively eliminated by adding a convective velocity so that the ocean surface fluxes would not be zero under windless conditions (Bradley et al. 1991; Fairall et al. 1995). 
The TOGA COARE bulk algorithm (surface layer flux module) was implemeted in the GCE model (Wang et al. 1996, 20001) and is called every three minutes $^{2}$ using the GCE model simulated wind, temperature, and moisture located at the lowest model grid level $(40$ to $85 \mathrm{~m})$. The momentum, latent and sensible heat fluxes derived from the TOGA COARE bulk algorithm are then used for the GCE model. The fluxes calculated by the TOGA COARE algorithm and by a simple aerodynamic formula will be compared and presented in a later section.

\subsection{Ocean Mixed Layer (OML) model}

The diurnal cycle in SST (skin SST) is largely driven by diurnal solar heating but modulated by other factors. For example, surface wind can enhance vertical mixing in the ocean surface layer, redistributing the incoming solar energy and therefore reducing the SST diurnal cycle. The cloud-radiative effect (cloud cover) can also reduce the diurnal cycle in SST. Convective downdrafts associated with deep convection often cool and dry the boundary layer and surface air and consequently increase the air-sea temperature and humidity differences and enhance the air-sea heat fluxes. Convectively generated (induced) surface wind (gusts) can also enhance air-sea fluxes. These convective processes could decrease SST and therefore modulate the SST diurnal cycle. Precipitation (fresh water) can also have an impact on the diurnal cycle of SST. Coupling a CRM with an ocean mixed layer (OML) model can provide a powerful tool for improving the understanding of the impact of precipitation and changes in the planetary boundary layer upon SST variation.

The essential physics of the OML model in this proposed task are similar to that of Kraus and Turner (1967) and Adamec et al. (1981) with some modifications (Sui et al. 1997a). The OML model solves equations for mixed-layer depth, temperature, and salinity. At the model's top boundary, surface longwave radiation, solar radiation, latent heating, and sensible heating are important forcing for the mixed-layer temperature. Surface precipitation and evaporation rates (P-E) affect mixed-layer salinity. At the mixed-layer base, an entrainment velocity is calculated based on Kraus and Turner's equation (1967) and modified by Sui et al. (1997a). Temperature and salinity below the mixed layer are also

2 Additional tests showed that surface precipitation differences between runs calling the flux algorithm every $7.5 \mathrm{~s}$ and every $180 \mathrm{~s}$ were small. 
calculated based on the primitive equations as described in $\mathrm{Li}$ et al. (1998). The mixed-layer model and the circulation model communicate with each other through the embedding technique of Admec et al. (1981). The model also includes a convective adjustment scheme to ensure static stability of the upper ocean. The depth of the model is $500 \mathrm{~m}$ with 33 non-uniform levels. A 1-m resolution is used in the top levels of the model and $50 \mathrm{~m}$ in the lower levels.

\section{Results}

\subsection{Goddard Microphysics}

(a) TOGA COARE and GATE squall line simulations using the 3ICE and 4ICE schemes

In the sensitivity tests of 3ICE and 4ICE schemes, simulations were made for two well documented tropical squall lines, the 12 September 1974 GATE (Szoke and Zipser 1986) and the 22 February 1993 TOGA COARE cases (Jorgensen et al. 1997). Both cases, TOGA COARE and GATE, (Table 6) have moderate convective available potential energy (CAPE), 1400 and $1600 \mathrm{~J} / \mathrm{kg}$, respectively. Tropical oceanic convective systems are typically associated with a moderate CAPE. While the TOGA COARE case has a very moist environment with a precipitable water of $6.05 \mathrm{~g} \mathrm{~cm}^{-2}$, the GATE case is substantially drier with a precipitable water of $4.80 \mathrm{~g}$ $\mathrm{cm}-2$. The sea surface temperature in the TOGA COARE case is higher than that in the GATE case. The environmental winds are also quite different between the two cases. In the TOGA COARE case, a fairly strong low level jet (about $12 \mathrm{~m} \mathrm{~s}^{-1}$ ) is present at a height of $2 \mathrm{~km}$, and there is a weak overturning upper tropospheric wind $\left(4 \mathrm{~m} \mathrm{~s}^{-1}\right)$ at about $10 \mathrm{~km}$. The GATE case has less shear in the lower troposphere, but there is a strong jet in the upper troposphere above $10 \mathrm{~km}$ (about $30 \mathrm{~m} \mathrm{~s}^{-1}$ ) in the same direction as the low level flow.

Figure 4 shows the surface rainfall simulated by the 3D GCE model using the 3ICE and 4ICE schemes for the TOGA COARE squall system. The use of different ice schemes does not have any significant impact on the organization of cloud systems. For example, an arc shape and the presence of vortices along the edges for the TOGA COARE squall system are both simulated by the 3ICE and 4ICE scheme. In addition, the northern portion of the squall system is stronger than its southern component. All these features are in good agreement with observation 
(Jorgensen et al. 1997). The propagation speed of the TOGA COARE squall system simulated by both schemes is about the same $\left(14 \mathrm{~m} \mathrm{~s}^{-1}\right)$ and about $2 \mathrm{~m} \mathrm{~s}^{-1}$ faster than observed. For the GATE squall system, the use of different ice schemes also does not have any significant impact on the organization of cloud systems (Fig. 5). The simulated GATE squall system shows more linear organization than the TOGA COARE squall case. Both 3ICE- and 4ICE-scheme simulated GATE squall systems decayed after $5 \mathrm{~h}$ into the model integration.

However, the different ice microphysical parameterizations can effect the surface precipitation for both cases. There is (about 30\%) less surface precipitation with the 4ICE scheme than the 3ICE scheme (Table 7). The total stratiform percentage (over $9 \mathrm{~h}$ ) is quite similar between the 3ICE and 4ICE runs (Table 7). However, the temporal evolution of stratiform rain during the life cycle of the squall systems in runs using $4 \mathrm{ICE}$ and 3ICE schemes is different. The 3ICE scheme produced more stratiform rain in the first $5 \mathrm{~h}$ of simulation time but less later in the simulation (see Figs. 3 and 4). This is because the various ice schemes lead to different vertical hydrometeors profiles (Fig. 6). Small ice particles (cloud ice and snow) with slow fall speeds $\left(1-3 \mathrm{~m} \mathrm{~s}^{-1}\right)$ are more dominant in the 4ICE scheme. The 3ICE scheme produces more and larger graupel (with $2-5 \mathrm{~m} \mathrm{~s}^{-1}$ fall speeds) in the convective towers and which is transported into the trailing portion of the squall system (i.e., stratiform region). These larger ice particles can melt and reach the surface in the stratform region. The smaller (but abundant) ice particles simulated in the 4ICE scheme require longer time to reach the surface. That is why the stratiform rain percentage is increased in the runs using the $4 \mathrm{ICE}$ scheme.

Note that more rainfall is simulated in the TOGA COARE squall line than in the GATE one. Also more stratiform precipitation is simulated in the TOGA COARE squall line (35\%) compared to the one for GATE $(24-27 \%)$. A moister large-scale environment associated with TOGA COARE is one of two major reasons for more rainfall and stratiform amount. The other reason is that warm rain processes are dominant in the GATE squall case but not in the TOGA COARE squall case. Note that $3 \mathrm{D}$ simulations have less $(12 \%$ and $5 \%$, respectively, for TOGA COARE and GATE) stratiform precipitation than 2D in both cases. Please see Wang et al. (2001) for more discussions and comparison between these GATE and TOGA COARE squall systems. 


\section{(b) New Saturation Techniques}

When supersaturated conditions are brought about, condensation or deposition is required to remove any surplus of water vapor. Likewise, evaporation or sublimation is required to balance any vapor deficit when subsaturated conditions come about in the presence of cloud. As the saturation vapor pressure is a function of temperature, and the latent heat released due to condensation, evaporation, deposition, and sublimation modifies the temperature, one approach has been to solve for the saturation adjustment iteratively. Soong and Ogura (1973), however, put forth an method that did not require iteration but for the water-phase only.

Tao et al. (1989) adopted the approach of Soong and Ogura (1973) and modified it to include the ice-phase. The saturation vapor mixing ratio between the temperature range of $O C$ and TOO (typically -30 to $-40 \mathrm{C}$ ) is taken to be a mass weighted combination of water and ice saturation values depending on the amounts of cloud and cloud ice present. Condensation/deposition or evaporation/sublimation then occurs in proportion to the temperature. Another approach is based on a method put forth by Lord et al. (1984) which weights the saturation vapor mixing ratio according to temperature between $0 \mathrm{C}$ and $\mathrm{T} 00$. Condensation/deposition or evaporation/sublimation is then still proportional to temperature. One other non-iterative technique treats condensation and deposition or evaporation and sublimation sequentially. Saturation adjustment with respect to water is allowed first for a specified range of temperatures followed by an adjustment with respect to ice over a specified range of temperatures. The temperature is allowed to change after the water phase before the ice phase is treated (this third saturation technique is termed the "new saturation technique"). All three approaches are available within the model.

In general, the overall cloud system structure and character are not sensitive to the different saturation schemes. This was found to be especially true in a midlatitude environment with strong instability (PRESTORM). However, for a tropical simulation (TOGA COARE), there were some subtle differences. Propagation speed was slightly higher using the Tao et al. (1989) technique $(0.25$ $\mathrm{m} / \mathrm{s}$ over the final $3 \mathrm{~h}$ of a $12 \mathrm{~h}$ simulation) while the Lord et al. (1984) method generated slightly fewer cells over the course of the same simulation time (12 h). 
The main differences, however, are primarily manifested in the cloud and cloud ice fields. Vertical cross-sections of cloud water content (Fig. 7) reveal that the first two methods, Tao et al. (1989) and Lord et al. (1984), allow cloud water to persist well into the trailing anvil and well above the freezing level while the new saturation technique restricts the cloud water more to the convective region and below the freezing level. Profiles of cloud and cloud ice content (Fig. 8) indicate that the biggest differences between the methods occur in the mixed phase region between the freezing level and about $-30 \mathrm{C}$. The new saturation technique contains significantly more cloud ice and almost no cloud water above the $-10 \mathrm{C}$ level compared to the other two methods. Although the other hydrometeor species, the overall storm structure and rainfall are not significantly effected, simulated microwave brightness temperatures could be effected. The new saturation technique appears to be the most reasonable solution (Personal communication Andrew Heymsfield).

\section{(c) Modification of Conversion of Cloud Ice to Snow in 3ICE schemes}

An important process in the budget for cloud ice is the conversion of cloud ice to snow as the ice crystals grow by vapor deposition in the presence of cloud water, usually referred to as the Bergeron process and designated PSFI (production of snow from ice) by Lin et al. (1983). As described by Braun et al. (2001), the formulation generally used in the parameterization is independent of relative humidity, which causes ice to be converted to snow even when the air is subsaturated with respect to ice. They propose two alternative formulations. In the first, the original formula is simply multiplied by an empirically derived relative-humidity dependent factor so that PSFI diminishes as the relative humidity approaches the ice saturation value. The second alternative formulation is derived directly from the equation for depositional growth of cloud ice (Rutledge and Hobbs 1983) used in the model. This formulation causes PSFI to diminish as the relative humidity approaches the ice saturation value, but also ensures physical consistency with the parameterization of depositional growth of cloud ice used in the model. The two alternative formulations produce relatively similar results since simulated ice clouds often have vapor mixing ratios near the ice saturation value so that PSFI is very small. Figure 9 shows examples of the snow and cloud ice distributions from two-dimensional simulations of a midlatitude squall line, one (Figs. 9a, 9b) using the original parameterization of 
PSFI and the other using the formulation based on the Rutledge and Hobbs (1983) depositional growth equation (Figs. 9c, 9d). The main differences include an increase in cloud-top height and a substantial increase in the cloud ice mixing ratios, particularly at upper levels in the cloud, using the new formulation of PSFI.

\section{(d) Spectral Bin-Model}

The spectral bin microphysics can be used to explicitly study the effects of atmospheric aerosol concentration on cloud development, rainfall production, and rainfall rates for deep tropical clouds. It is specially designed to take into account the role of atmospheric aerosols on cloud evolution and precipitation formation. The droplet nucleation is described on the basis of analytical calculations for supersaturation, which are used to calculate the sizes of activated aerosol particles and the corresponding sizes of nucleated droplets. The spectral bin microphysical model is very expensive from a computational point of view, and has only been implemented into the $2 \mathrm{D}$ version of the GCE at the present time.

In this study, the evolution of deep tropical clouds is simulated for two cases under identical thermodynamic conditions (West Pacific warm pool region), but with different concentrations of CCN: a low "clean" concentration (Nlow) and high "dirty" concentration (Nhigh). The $\mathrm{CCN}$ concentration is represented as $\mathrm{N}=\mathrm{ASB}$, where $\mathrm{S}$ is supersaturation in $\%, \mathrm{~A}=69$ and $582 \mathrm{~cm}-3$, and $\mathrm{B}=0.462$ and 0.308 for the Nlow and Nhigh cases, respectively. Besides the initial aerosol concentration differences, the results (Fig. 10) indicate that the low CCN concentration case produces rainfall at the surface sooner than the high CCN case, but has less cloud water mass aloft. Because the spectral bin model explicitly calculates and allows for examination of both the mass and concentration of species for each size category, a detailed analysis of the instantaneous size spectrum can be obtained for the two cases (Fig. 11). Here it is shown that since the low CCN case produces fewer droplets, larger sizes develop due to greater condensational and collectional growth, leading to a broader size spectrum in comparison to the high CCN case.

Figure 12 shows that the simulation with low $\mathrm{CCN}$ produced approximately half the cloud water mass than the run with high $\mathrm{CCN}$, but twice the rain water mass. The low $\mathrm{CCN}$ case also has higher rain water contents reaching the surface, 
which indicates that low $\mathrm{CCN}$ cloud systems are more efficient precipitation producers for these types of systems. Rosenfeld (2000) used NOAA/AVHRR and TRMM/VIS observations to infer the microstructure of developing and mature convective clouds as a function of height. His results demonstrated that smoke and air pollution may act to suppress both liquid-phase and ice processes involved in precipitation development. These preliminary numerical results (although just an idealized case) are in good agreement with the observations, indicating that the microstructure of clouds depends strongly on cloud-aerosol interactions.

\subsection{Radiative Processes}

\section{(a) Impact of radiative transfer processes on precipitation}

The 2D GCE Model has been used to perform a series of sensitivity tests to identify which is the dominant cloud-radiative forcing mechanism with respect to the organization, structure and precipitation processes for both a tropical and a midlatitude mesoscale convective system (Tao et al. 1996). Figure 13 shows a schematic diagram demonstrating the impact of cloud-radiation mechanisms on surface precipitation for both cases. The GCE model results indicated that the dominant process for enhancing the surface precipitation in both squall cases was the large-scale radiative cooling. However, the overall effect is really to increase the relative humidity and not the CAPE. Because of the high moisture in the tropics, the increase in relative humidity by radiative cooling can have more of an impact on precipitation in the tropical case than in the midlatitude case. The large-scale cooling led to a $36 \%$ increase in rainfall for the tropical case. The midlatitude squall line with a higher CAPE and lower humidity environment was only slightly affected $(7 \%)$ by any of the longwave mechanisms. The mechanisms associated with differential cooling between clear and cloudy regions and with cloud-top cooling and cloud-base warming are less important than the large-scale longwave radiative cooling.

\section{(b) Diurnal variations of precipitation in tropical oceans}

The diurnal variation of precipitation processes over the tropics is a well recognized but poorly understood phenomenon. Improved understanding of this diurnal cycle is needed in order to make reliable monthly estimates using twice 
daily satellite observations (i.e., TRMM and SSM/I). The diurnal cycle of precipitation has been studied using surface rainfall data, radar reflectivity data, and satellite-derived cloudiness and precipitation. For example, observations indicate a diurnal cycle with a nocturnal-early morning precipitation maximum over open oceans and an afternoon-evening maximum over land (Kraus 1963; Gray and Jacobsen 1977; Randall et al. 1991 and many others).

The 2D GCE model has been used to determine the "mechanisms" associated with the diurnal variation of precipitation processes (Sui et al. 1998). Figure 14 shows the simulated diurnal variation of surface rainfall obtained from three sensitivity tests. The run that did not allow for the diurnal variation of radiative processes (Run 3 ) did not produce a diurnal variation of rainfall. Note that the diurnal variation of rainfall was simulated even when the diurnal variation of SST was not allowed (Run 1). However, the maximum rainfall was shifted from $2 \mathrm{AM}$ to 3-6 AM. These results suggested that the diurnal variation of sea surface temperature could modulate rainfall processes, but it only may play a secondary role in diurnal variation. Sui et al. (1998) also found that modulation of convection by the diurnal change in available water as a function of temperature was responsible for a maximum in rainfall after midnight. This simply implies that the increase (decrease) in surface precipitation associated with longwave cooling (solar heating) was mainly due to an increase (decrease) in relative humidity (Fig. 15). A similar conclusion was found by Tao et al. (1996). In addition, the simulated rainfall (Run 2) was similar to observed variation estimated by radar in large-scale disturbed conditions. Please see Sui et al. (1998) and Tao et al. (1996) for more discussions and comparison with observations and with results from other cloud resolving models.

The physical processes responsible for diurnal precipitation were found to be different in another CRM study. Liu and Moncrieff (1998) showed that the direct interaction of radiation with organized convection was the major process that determined the diurnal variability of rainfall. Their results indicated that well (less) organized cloud systems can have strong (weak) diurnal variations in rainfall. They also suggested that ice processes are needed. The model set-ups between Sui et al. (1998) and Liu and Moncrieff (1998) are quite different, however. In Liu and Moncrieff (1998), the horizontal momentum was relaxed to its initial value which had a strong vertical shear. On the other hand, the horizontal wind 
was nudged to time-varying observed values in Sui et al. (1998). Consequently, only long-lived squall lines (or fast-moving convective systems) were simulated in Liu and Moncrieff (1998) over the entire simulation [Fig. 16(a)]. In Sui et al. (1998), however, their simulated cloud systems had many different sizes and various life cycles [Fig. 16(b)]. Additional GCE model sensitivity tests (with and without the diurnal variation of radiative processes) were conducted using the model set-up of Liu and Moncrieff (1998). The results still indicated that the modulation of relative humidity by radiative processes was the main reason for the diurnal variation of precipitation. Organization of cloud systems only played a secondary role in the diurnal variations of precipitation.

\subsection{Land Surface Processes}

\section{(a) Landscape-generated deep moist convection}

The coupled GCE-PLACE atmosphere-land surface model was used to study the generation of deep moist convection over heterogeneous landscapes (Lynn et al. 1998). Two soundings on July $27^{t h}, 1991$, one located on the east coast and one located on the west coast of Florida, were taken from CaPE (the Convection and Electrification Experiment). They were averaged to obtain a mean sounding for an east-west cross section over the peninsula at 6 LST. The sounding had a small initial convective available potential energy (CAPE) of $740 \mathrm{~kJ} \mathrm{~kg}^{-1}$, but a relatively low lifting condensation level pressure (an LCL of $1010 \mathrm{mb}$ with a surface pressure of $1018 \mathrm{mb}$ ), low level of free convection (LFC; $839 \mathrm{mb}$ ), and high equilibrium level (EL; 190 mb). Thus, upon warming/moistening of the planetary boundary layer, the initial sounding was conducive to the development of deep moist convection.

A total of 28 2D GCE-PLACE model simulations were performed by alternating patches of dry and wet soil for various profiles of background wind. Results indicated that rainfall occurred most intensely along the sea-breeze-like fronts, which formed at patch boundaries. Figure 17 shows the relationship between average accumulated rainfall versus patch size. The simulated rainfall total increased sharply with increaing patch size, but had a peak between the simulations with patch sizes of 128 and $256 \mathrm{~km}$. These results correspond well with numerical results obtained in simulations with a dry planetary boundary 
layer at midlatitudes by Pielke et al. (1991), Avissar and Chen (1993), and Lynn et al. (1995a), and for shallow convection obtained by Chen and Avissar (1994). It was also found that the strongest mesoscale circulations and rainfall were generated over patches similar in size to the local Rossby radius of deformation $(\sim 128 \mathrm{~km})$. This is because forcing by the land surface corresponded well with the preferred scale of circulation, as determined by the local Rossby radius.

A cross-section of GCE model simulated Convective Available Potential Energy (CAPE) versus time and distance is shown in Fig. 18. The largest CAPE evolved above the wet patch, while the smallest CAPE evolved over the dry patch. The model results clearly indicated that the largest potential for deep convection occurred over the wet ground, as is consistent with the results obtained in a onedimensional study by Segal et al. (1995). However, the most rainfall did not occur where the CAPE was largest. Instead, the heaviest rainfall occurred along the seabreeze-like fronts - where the CAPE was of intermediate value. These results are in contrast to those obtained by Clark and Arritt (1995), who also used a onedimensional model to study moist convection. Thus, these results suggested that there was a need to take into account both the distribution of CAPE and the dynamic forcing by landscape-generated mesoscale circulations on moist convection.

The coupled 3D GCE-PLACE atmosphere-land surface model was also used to investigate the triggering of moist convection over heterogeneous west-to-east land surface domains [Lynn et al, 2001(a)]. Various land surface domains were used to provide the surface boundary conditions. There are (different) alternating distributions of patches of dry and wet ground along the west-to-east direction. These patches are distributed uniformly in the north-to-south direction. Thus, the mesoscale circulation is generated by essentially two-dimensional patches. Yet, the domain is wide enough to simulate three-dimensional turbulence and the horizontal west-east structure of the mesoscale circulations. A Fourier transform is used to filter the data and obtain a distribution of mesoscale and turbulent perturbations. Figure 19 shows an example of filtered atmospheric fields (from 3D simulations) obtained over wet and dry patches with a wavelength of $128 \mathrm{~km}$. The mesoscale horizontal and vertical wind, potential temperature, and specific humidity fields correspond very well with observations of sea-breezes and sea- 
breeze-like circulations produced with mesoscale models (Finkele et al. 1994; Lynn et al. 1995a).

Figure 20 shows 3D GCE results from two cases, with and without a background wind: one with large patches and the other with a number of small patches. The results indicated that rainfall and its duration increase with increasing patch size, but isolated rain clusters can occur even over small patches. These results suggest that the domain accumulated rainfall is a function of both patch size and patch number. Moreover, the magnitude of the rainfall is sensitive to the background wind. A background wind increases turbulent dissipation, which can reduce the generation of landscape generated rainfall by mesoscale perturbations over small patches. On the other hand, a background wind blowing against the sea-breeze-like front on the downwind side of the dry patch can lead to an intensification of the front. Therefore, there is the need to take into account both the distribution of wet-dry patches and dynamic forcing by landscape generated mesoscale circulations (LGMCs) on moist convection. The GCE model results also indicated that a monotonic (linear) relationship exists between the local accumulated rainfall over individual patches and the size of these patches, but not the domain accumulated rainfall and domain averaged patch size. Thus, cumulus parameterizations and their trigger functions for heterogeneous landscapes should be applied over multiple, individual patches within the domain, rather than to a single patch of average size.

Based on the results from the 3D GCE-PLACE atmosphere-land surface coupling model, Lynn et al. [2001(a)] analyzed and derived a number of dimensionless numbers that can be used in parameterizations for the parcel's triggering variables used in the mesoscale model. They, Lynn and Tao (2001) then used zero-order and first-order closure to parameterize these fluxes.

\section{(b) Non-homogeneity of soil/vegetation}

An idealized Florida peninsula with straight coastlines was studied by using the 3D GCE-PLACE model (Baker et al. 2001). A sandy loam soil type and tall broadleaf trees with ground cover were considered. Sensitivity tests comparing variable initial soil moisture (Fig. 21) and horizontal averaged initial soil moisture were performed to investigate the influence of soil moisture on sea-breeze 
initiated precipitation. The results indicated that the distribution of initial soil moisture influences the timing and location of subsequent precipitation. Soil moisture acts as a moisture source for the atmosphere, and preferentially focuses heavy precipitation over existing wet soil. A positive feedback mechanism between soil moisture and precipitation has been observed in many observational and numerical studies (e.g., Segal et al. 1995;Clark and Arritt 1995 and others). A key prerequisite for this positive feedback is a moist atmosphere. In this idealized Florida sea-breeze case, relative humidities roughly $80-85 \%$ exist initially at 0600 LST from the surface to $500 \mathrm{mb}$. The atmosphere is primed to over-turn under these moist conditions, and soil moisture gives the atmosphere a boost in convective instability. If the atmosphere were relatively dry, large values of soil moisture would reduce the sensible heat flux to the atmosphere and would likely inhibit convective development.

Soil moisture-induced mesoscale circulations are present in the simulation, but they have little impact on the development of heavy precipitation. This conclusion is different from previous GCE model [Lynn et al. 1998, 2001(a)] and other numerical simulations (i.e., Yan and Anthes 1998; Avissar and Liu 1996). Soil moisture gradients in this Florida sea-breeze case are much smoother than step-wise gradients in previous idealized simulations, perhaps inhibiting development of strong mesoscale circulations. A strong lake breeze circulation caused by Lake Okeechobee was simulated, and it affects the timing and location of heavy precipitation.

Baker et al. (2001) examined the impact of initial soil moisture on sea-breeze initiated precipitation. The total sensible and latent heat fluxes from their two sensitivity tests (initial variable or uniform soil moisture distribution) were not the same. Two cases are also considered to assess the impact of non-homogeneity of soil/vegetation on precipitation. The first run is initialized with inhomogeneous soil moisture based on the off-line PLACE Model (termed Case A). The second run (Case B) uses uniform and averaged surface fluxes based on Case A. Ocean fluxes are the same in the two cases. Random perturbations in sensible and latent heat of $+-5 \mathrm{~W} / \mathrm{m}^{\wedge} 2$ were added to the average fluxes in Case $B$ for the first three hours of the simulation to produce random fluctuations in forcing. In these two runs, the total sensible and latent heat fluxes over the model domain and simulation period were almost identical. 
There are several key differences between the simulations. First, the peak accumulated rainfall in Case B (homogeneous) is larger by $33 \%$ (66.4 mm vs. 49.7 $\mathrm{mm}$ ) but the area averaged rainfall is less in case B by $10 \%(3.8 \mathrm{~mm}$ vs. $4.2 \mathrm{~mm}$ ). More area is covered by rainfall in Case A than in Case B. Second, rainfall begins 1 hour earlier in Case A. Third, Case B exhibits a secondary peak in rainfall late in the day (Fig. 22). The cause of this secondary peak is likely a strong cell that developed late in the day.

\subsection{Ocean Flux Processes}

The 22 February 1993 TOGA COARE squall case discussed in Section 4.1 was also simulated to investigate the impact of ocean surface fluxes on organization and precipitation processes. Both the TOGA COARE flux algorithm and a simple bulk aerodynamic method [such as those by Malkus (1962) and Roll (1965)] that have been used frequently in cloud-resolving models as well as in hurricane models are used in the GCE model for comparison. The major difference between the TOGA COARE algorithm and a simple bulk aerodynamic method is that the drag coefficient only depends on the wind speed in the simple bulk aerodynamic method formulation, whereas the drag coefficient depends on both dynamic and thermal stability functions through the Monin-Obukhov similarity theory in the TOGA COARE flux algorithm (see Section 3.4).

Table 8 lists latent and sensible heat fluxes for disturbed (convective) and undisturbed (cloud-free) areas from observations and from the 2-D GCE model simulation using the TOGA COARE flux algorithm. LeMone et al. (1995) computed the sensible and latent heat fluxes from aircraft measurements at a height of $158 \mathrm{~m}$. In order to make a valid comparison, the fluxes using the model generated wind, temperature, and moisture at $156 \mathrm{~m}$ (second model grid height) were used. These results agree well with the observations. In addition, the flux values computed using model data at the $20 \mathrm{~m}$ level also compared favorably with those measured at $10 \mathrm{~m}$ during a pilot cruise (Young et al. 1992). The results showed great similarity in the convective wake characteristics between individual wakes and in the composite time series, despite the observations coming from different locations and seasons. The GCE model flux calculations using the TOGA COARE algorithm and the cloud model predicted variables give slightly higher 
values in the convective region, probably due to the stronger than average convection in this squall line case. Wang et al. (1996) also showed that among the heat and momentum fluxes, the latent heat flux is the most important component for cloud development.

The sensible and latent heat fluxes in the disturbed area are stronger for a $3 \mathrm{D}$ simulation $^{3}$ (Table 8 ). The main reason for the difference is that the convective activity (i.e., strengths of active convective updrafts and downdrafts) is much stronger in the 3D simulation than the 2D. A stronger cool pool is also simulated in the $3 \mathrm{D}$. In addition, a larger convective region is simulated in the $3 \mathrm{D}$ GCE model. The gradient of temperature and mixing ratio of water vapor between the sea surface and the modeled atmosphere (planetary boundary layer) is also stronger in 3D model.

The 3D GCE model results using the simple bulk aerodynamic formula are also shown in Table 8 . There is approximately a $20 \%$ increase in surface fluxes using the bulk aerodynamic formula compared to the TOGA COARE flux algorithm. The model domain averaged CAPE is also increased significantly in the run using the bulk aerodynamic formula. The results from the TOGA COARE flux algorithm are in better agreement with observations. These results are in good agreement with the results from the 2D GCE model sensitivity tests (Wang et al. 1996). The exchange coefficients in the bulk aerodynamic formula method and in the TOGA COARE flux algorithm are different in two ways. First, in the lower wind speed region (less than $4 \mathrm{~m} \mathrm{~s}^{-1}$ ), the exchange coefficients in the TOGA COARE flux algorithm increase with decreasing wind speed in order to account for the convective exchange at low wind speeds. Secondly, the coefficients in the bulk aerodynamic formula linearly increase with respect to the wind speed, while the $\mathrm{CE}_{\mathrm{E}}$ and $\mathrm{C}_{\mathrm{H}}$ in the TOGA COARE algorithm go down with wind speed when wind speed is greater that $5 \mathrm{~m} \mathrm{~s}^{-1}$ [see Fairall et al. (1995)]. These differences in the exchange coefficients probably reflect the differences in the results between runs using the TOGA COARE flux algorithm and a simple bulk aerodynamic formula.

Figure 23 shows the rainfall and surface latent heat flux values using the TOGA COARE flux algorithm and the simple bulk aerodynamic method. The

3 The sensitivity tests were performed using the 2D GCE model with $42.5 \mathrm{~m}$ vertical resolution in the lowest model grid. The conclusion between 2D and 3D GCE model was still valid. 
different flux algorithms do not effect the organization of the squall system. Both runs also show a large peak in latent heat flux at the leading edge of the convection, about 4-5 times the value in the clear area. This is due to the stronger winds and colder temperature in the cloudy convective region. The 9-hour rainfall total simulated with the TOGA COARE flux algorithm is about $73 \%$ of the rainfall amount using the bulk aerodynamic method. Larger surface fluxes cause more rainfall (or precipitation processes). A sensitivity study using the GCE model by Wang et al. (2001) indicated that surface fluxes from the large clear area are more influential to the rain fall amount than the fluxes from the disturbed convective area because the moisture supply to the convective system is mainly from the clear area ahead of the convective system. The stratiform amounts between these two runs are very similar (about $35 \%$ ). Horizontal wind shear may play a major role in determining the organization and the amount of the stratform rain.

Relatively good agreement in surface fluxes may imply that the modeled wind, temperature, and moisture fields in the lower troposphere are qualitatively realistic. For the same TOGA COARE case, Jorgensen et al. (1995) reported a $15 \mathrm{~m}$ $\mathrm{s}^{-1}$ wind speed at the leading edge of the convective line. Our 3D simulation gives similar results. The wind speed is $16 \mathrm{~m} \mathrm{~s}^{-1}$; the cooling is $\sim 3.8^{\circ} \mathrm{K}$; and, the drying is $3 \mathrm{~g} / \mathrm{kg}$ at the leading edge of the convective line. For a different TOGA COARE case, Parsons et al. (1994) reported a $4.5^{\circ} \mathrm{C}$ cooling, a $10-12 \mathrm{~m} \mathrm{~s}^{-1}$ wind speed and a $2 \mathrm{~g} / \mathrm{kg}$ drying at the leading edge of the convection.

\subsection{Ocean Mixed Layer Processes}

The coupled GCE-OML model has been used to investigate the impact of precipitation on the upper ocean in the western Pacific warm pool during TOGA COARE ( $\mathrm{Li}$ et al. 2000). The GCE model-simulated diabatic source terms, radiation (QR), surface fluxes of sensible and latent heat, and the precipitation minus evaporation (P-E) rates in the atmosphere (net freshwater flux) were used as input for the OML model. TOGA-COARE observations are used to provide the initial and boundary conditions for the GCE-OML model as well as to verify the GCEOML results.

Several major convective events occurred around 11-16 and 20-25 December 1992, mainly due to low-level large-scale convergence of easterlies and westerlies. 
However, the synoptic conditions were different for these two December periods. Easterly flow prevailed at low levels from near the date line westward to the IFA, and convection over the IFA arrived from the east with an easterly surge on 11-16 December. Both cases show a similar order of magnitude of peak heating, $10 \mathrm{~K}$ day $^{-1}$ between 350 and $500 \mathrm{mb}$. During 21-24 December, there was a greater contribution to heating from stratiform precipitation caused by the increased wind shear [see Lin and Johnson (1996)]. There was less of a stratiform contribution for the December 11-16 convective episode. In middle and late February, westerly flow, although weaker than that in early February and December, still dominated levels below $500 \mathrm{mb}$. Stratiform clouds dominated the IFA during this period although shallow cumuli were also present (Lin and Johnson 1996). Three different convective episodes, December 10-17, 1992, December 19-27, 19924, and February 9-13, 1993 have beed simulated using the GCE model (Tao et al. 2000). Recently, these three episodes have been studied using the coupled 2D GCE-OML model to study the impact of precipitation and changes in the planetary boundary layer upon SST variation.

Sea surface temperature varies diurnally in all three episodes are mainly due to the diurnal variation of solar radiation (Fig. 24). This diurnal variation in sea surface temperature (SST) then forms a diurnal variation in thermal instability for the upper sea surface layer: a thermally stable layer during daytime due to SST warming by solar radiation and a thermally unstable layer at night due to SST cooling by infrared (longwave) radiation. Consequently, strong (deep) surface layer mixing occurs at nighttime due to thermal instability, while mixing is confined to a shallow layer in the daytime due to thermal stability. Time variation of the horizontal-mean mixed-layer depth (h) is hence found out of phase with that of SST in the three episodes (Fig. 25). The strong nocturnal mixing may bring up the colder sea water, which moves up from below the mixed layer through entrainment, and reduce SST.

This mixed-layer depth, further modified by the surface wind speed, is found to fluctuate with small amplitude (shallow mixed-layer) in episode 1 (December 10-17, 1992) with weak surface wind speeds, and oscillate with large amplitude (deep mixed-layer) in both episodes 2 (December 19-27, 1992) and 3

4 This period has also been used by the GCSS working group 4 (WG4) model intercomparison project for CRMs and SCMs. 
(February 9-13, 1993) due to strong surface wind speeds (westerlies). Note that the peak $\mathrm{h}$ takes place shortly after the onset of a westerly wind burst. However, the diurnal oscillation in SST is modified by the mixing process in an opposite sense; the highly (lightly) oscillating SST with large (small) amplitude in episode 1 (3) corresponds to weak (strong) mixing in the ocean surface layer.

Time evolution of horizontal-mean surface salinity $(S)$ is found positively correlated with that of the mixed layer depth for all three episodes (Fig. 26). Stronger (weaker) mixing in the boundary layer brings up more (less) salty water from below into the upper sea surface layer and generates higher (lower) surface salinity. Actually, salinity (through diffusion) also plays an important role in upper layer mixing. For example, in episode 3, high surface salinity tends to diffuse downward and intensifies the mixing process, while low surface salinity found in episode 1 might significantly stabilize the mixing process (i.e., very shallow $\mathrm{h}$ ). In terms of impacts on mixed-layer depth, the salinity effect may even play a stronger role than the thermal effect does because the expansion coefficient of ocean water density by salinity $(0.000751 /$ PSU) is larger than that by temperature $(0.00021 / C)$ while variations in temperature and salinity are comparable in magnitude.

The numerical SST simulations generally agree well with SST observations, while the salinity simulations differ from the observations both qualitatively and quantitatively. The discrepancy in salinity may be possibly due to poor salinity observations or the biased numerical precipitation quantities.

\section{Summary and Future Works}

The Goddard Cumulus Ensemble (GCE) model is a multi-dimensional nonhydrostatic dynamic/microphysical cloud resolving model. Recently, five major improvements were made to the GCE model. (i) Improved microphysical schemes have been developed namely a four-class, multiple-moment, multiple-phase ice scheme, which resulted in improved agreement with observed radar and hydrometeor structures for convective systems simulated in different geographic locations without the need for adjusting coefficients. This four-ice scheme was recently implemented into the three-dimensional version of the GCE model. A spectral bin microphysics scheme has also been implemented into the GCE model. 
(ii) Solar and infrared radiative transfer processes have been included in the model, which have been used to study the impact of radiation upon the development of clouds and precipitation and upon the diurnal variation of rainfall for tropical and midlatitude squall systems. (iii) Land surface processes were incorporated into the model to study the initiation and organization of convection, which formed in response to landscape heterogeneity represented by a land surface model. (iv) Ocean surface processes were also incorporated to investigate their impact upon the intensity and development of organized convective systems. (v) An ocean mixed layer model has been coupled to the GCE model to assess and establish the relationship between precipitation and sea surface temperature variation and the potential impact upon climate change scenarios. In this paper, these GCE model improvements were described as well as their impact on the development of precipitation events from various geographic locations. The performance of these new physical processes were examined by comparing the model results with observations. The GCE model was used to generate cloud ensembles for several different climatic regimes. These were compared with observations and results from other cloud resolving models in Tao (2001).

During the past 25 years, observational data on atmospheric convection has been accumulated from measurements by various means, including radars, instrumented aircraft, satellites, and rawinsondes in special field observations (e.g., GATE, PRESTORM, TOGA COARE 5 and several others). This has made it possible for cloud resolving modelers to test their simulations against observations, and thereby improve their models. In turn, the models have provided a necessary framework for relating the fragmentary observations and helping to understand the complex physical processes interacting in atmospheric convective systems, for which observations alone still cannot provide a dynamically consistent four-dimensional picture. The past decades have also seen substantial advances in the numerical modeling of convective clouds and mesoscale convective systems (e.g., squall-type and non-squall-type convective systems), which have substantially elucidated complex dynamical cloud-

5 GATE stands for GARP (Global Atmospheric Research Program) Atlantic Tropical Experiment, PRE-STORM for Preliminary Regional Experiment for Storm Central, and TOGA COARE for Tropical Oceans Global Atmosphere (TOGA) - Coupled Ocean Atmosphere Response Experiment (COARE). 
environment interactions in the presence of varying vertical wind shear. Many important and complex processes (which require extensive computations), such as ice-microphysics and radiative transfer, can now be simulated to a useful (but still oversimplified) degree in these numerical cloud models. There is much more work to be done comparing simulated cloud systems over various types of land and vegetation environments, ranging from arid to jungle. Recently completed field programs (DOE/ARM, TRMM LBA, TRMM KWAJEX and NASA CAMEX6) could provide a good opportunity to orchestrate combined observational and numerical studies of convective systems. These large-scale field campaigns can provide some of the desperately needed observations for key locations. These observations can guide and correct existing microphysical schemes used in the GCE model and other CRMs.

The GCE model using the spectral bin-microphysics can be used to study cloud-aerosol interactions and nucleation scavenging of aerosols, as well as the impact of different concentrations and size distributions of aerosol particles upon cloud formation. These findings will, in turn, be used to improve the bulk parameterizations. With the improved GCE model (and other CRMs), it is expected to lead to a better understanding of the mechanisms that determine the intensity and the formation of precipitation for a wide spectrum of atmospheric phenomenon (i.e., clean or dirty environment) related to clouds. An exponentially increasing computer resource has resulted in time integrations increasing from hours to days, domain grids boxes (points) increasing from less than 2000 to more than 2,500,000 and 3-D models becoming increasingly prevalent. The GCE model (and other CRMs) is now at a stage where it can provide reasonably accurate statistical information of the sub-grid, cloud-resolving processes now poorly parameterized in climate models and numerical prediction models. However, Cotton (2001) has discussed some limitations (i.e., prediction of ice particle concentrations, initial broadening of cloud droplet spectra in warm clouds, details of hydrometeor spectra evolution, quantitative simulations of entrainment rates) of current cloud resolving models. These limitations (or deficiencies) must be resolved in the coming years.

6 DOE/ARM stands for Department of Energy Atmospheric Radiation Measurement Program (Oklahoma and Pacific), TRMM for Tropical Rainfall Measuring Mission, LBA for Large Scale Biosphere-Atmosphere Experiment (S. America), KWAJEX for Kwajalein Experiment (W. Pacific) and CAMEX for Convection and Moisture Experiment (Florida). 
The GCE model (and other CRMs) allows explicit cloud-radiation and airsea interactive processes. However, the GCE model can only be used for idealized simulations (i.e., no feedback between clouds and their large-scale environment, cyclic lateral boundary conditions, and idealized initial conditions). The use of a regional scale model is required to examine the results (or performances) obtained from the GCE model. Some of the GCE model improvements presented in this paper have been implemented into a regional scale model (Penn State/NCAR MM5). For example, Lynn et al. (2001b) have tested the MM5-PLACE performance for sea-breeze generated deep convection over the Florida peninsula during the Convection and Precipitation Electrification Experiment (CaPE). They indicated that the land processes, initial soil moisture and planetary boundary layer can have a major impact on the sea breeze, lake breeze and moist convection. Liu et al. (1999), recently, used the MM5 with multiple-nested grids from 54 to $6 \mathrm{~km}$ to simulate Hurricane Andrew (1992). Their results suggested that the Goddard 3ICE scheme produced a more realistic eye structure, surface pressure, and spiral rain bands compared to the experiment with the 2ICE scheme. They suggested that graupel occurred in the eye wall which has a faster fall speed than snow. The cloud updrafts therefore have less loading and become stronger in the middle and upper troposphere. Consequently, downdrafts in the eye become stronger, and the associated warming is better simulated. Kuo et al. (1996), Yang et al. (2000) and Tao et al. (2001) showed that the Goddard 3ICE scheme produces more rainfall than a two-class ice (2ICE) scheme. Tao et al. (2001c) also examined the performance of the Goddard radiation scheme for heavy precipitation episodes that occurred in Taiwan (with complex terrain). Their results indicated that the Goddard multiple broad-band radiative transfer model can reduce the amount of precipitation compared to a single broad-band (emissivity) radiation model. The emissivity radiation model's longwave radiative cooling is over $-6 C$ compared to $-4 C$ in the Goddard radiation scheme near the surface for the cloud-free region. The stronger lower tropospheric cooling can further increase the relative humidity. In addition, stronger cooling near the surface can contribute to stronger radiative destabilization. Both factors consequently can provide a more favorable thermodynamic condition for cloud to form and, consequently, lead to more rainfall. The Goddard Physical Packages discussed in this paper are being implemented into a new Weather Research Forecast (WRF) model. The performance of these Goddard Physical Packages will be compared to other 
sophisticated physical packages implemented into the WRF. It is also planned to use the MM5 and WRF to study multiscale interactive processes (using a two-way interactive nesting technique).

\section{Acknowledgments}

This work is mainly supported by the NASA Headquarters Atmospheric Dynamics and Thermodynamics Program and the NASA Tropical Rainfall Measuring Mission (TRMM). The authors are grateful to Dr. R. Kakar at NASA headquarters for his support of this research.

Acknowledgment is also made to the NASA/Goddard Space Flight Center for computer time used in this research. 


\section{References}

Ackerman, T. P., K.-N. Liou, F. P. J. Valero and L. Pfister, 1988: Heating rates in tropical anvils. J. Atmos. Sci., 45, 1606-1623.

Adamec, D., R. L. Elsberry, R. W. Garwood and R. L. Haney, 1981: An embedded mixed-layer ocean circulation model. Dyn. Atmos. Oceans, 6(2), 69-96.

Adler, R. F., H.-Y. Yeh, N. Prasad, W.-K. Tao and J. Simpson, 1991: Microwave rainfall simulations of a tropical convective system with a three-dimensional cloud model. J. Appl. Meteor., 30, 924953.

Avissar, R., and F. Chen, 1993: Development and analysis of prognostic equations for mesoscale kinetic energy and mesoscale (subgrid-scale) fluxes for large scale atmospheric models. J. Atmos. Sci., 50, 3751--3774.

Baker, R. D., B. H. Lynn, A. Boone, W.-K. Tao and J. Simpson, 2001: The influence of soil moisture, coastline curvature, and the land-breeze circulation on sea-breeze initiated precipitation. J. of Hydrometeorology, (in press).

Betts, A. K., 1990: Greenhouse warming and the tropical water vapor budget. Bull. Amer. Meteor. Soc., 71, 1465-1467.

Boone, A. and P. J. Wetzel, 1999: A simple scheme for modeling sub-grid soil texture variability for use in an atmospheric climate model. J. Met. Soc. Japan, 77, 317-333.

Bott, A., 1998: A flux method for the numerical solution of the stochastic collection equation J. Atmos. Sci., 55, 2284-2293.

Bradley, E. F., P. A. Coppin, and J. S. Godfrey, 1991: Measurements of sensible and latent heat flux in the western tropical Pacific Ocean. J. Geophys. Res., 96, 3375-3389.

Braun, S. A., B. S. Ferrier and W.-K. Tao, 2001: Parameterization of depositional growth of cloud ice in a bulk microphysical model, $J$. Atmos. Sci., (submitted).

Businger, J. A., J. C. Wyngaard, Y. Izumi, and E.F. Bradley, 1971: Flux profile relationships in the atmospheric surface layer. J. Atmos. Sci., 28, 181-189.

Businger, J. A., 1973: Turbulent transfers in the atmospheric turbulence. Workshop on Micrometeorology, Amer. Meteor. Soc., 67-100.

Chen, F., and R. Avissar, 1994: Impact of land-surface moisture variability on local shallow convective cumulus and precipitation in large-scale models. J. Appl. Meteor., 33, 1382--1401.

Chou, M.-D., 1984: Broadband water vapor transmission functions for atmospheric IR flux computation. J. Atmos. Sci., 41, 1775-1778.

Chou, M.-D., 1986: Atmospheric solar heating rate in the water vapor bands. J. Climate Appl. Meteor., 25, 1532-1542. 
Chou, M.-D. and L. Kouvaris, 1991: Calculations of transmission functions in the IR CO2 and O3 Bands. J. Geophys. Res., 96, 9003-9012.

Chou, M.-D., and M. J. Suarez, 1994: An efficient thermal infrared radiation parameterization for use in general circulation models. NASA Tech. Memo. 104606, 85 pp.

Chou, M.-D., W. Ridgway, and M.-H. Yan, 1995: Parameterizations for water vapor IR radiative transfer in both the middle and lower atmospheres. J. Atmos. Sci. 52, 1159-1167.

Chou, M.-D., M. J. Suarez, C.-H. Ho, Michael M.-L. Yan, and K.-T. Lee, 1998: Parameterization for Cloud Overlapping and Shortwave Single-Scattering Properties for Use in General Circulation and Cloud Ensemble Models. J. Climate, 11, 202-214.

Chou, M.-D., K.-T. Lee, S.-C. Tsay, and Q. Fu, 1999: Parameterization for cloud longwave scattering for use in atmospheric models. J. Climate, 12, 159-169.

Chou, M. D., and M. J. Suraez, 1999: A shortwave radiation Parameterization for atmospheric studies. 15, NASA/TM-104606. pp40.

Clark, C.A, and R.W. Arritt, 1995: Numerical Simulations of the effect of soil moisture and vegetation cover on the development of deep convection. J. Appl. Meteor., 34, 2029-2045.

Cotton, W. R., 2001: Cloud modeling from days of EML to the present - Have we made progress? AMS Meteorological Monographs - Symposium on Cloud Systems, Hurricanes and TRMM, (accepted).

Emde, K. and U. Wacker, 1993: Comments on the relationship between aerosol spectra, equilibrium drop size spectra, and CCN spectra. Beitr. Phys. Atmosph., 66, 157-162.

Fairall, C., E.F. Bradley, D.P. Rogers, J.B. Edson, and G. S. Young, 1996: Bulk parameterization of airsea fluxes for TOGA COARE. J. Geophy. Res., 101, 3747-3764.

Ferrier, B. S., 1994: A double-moment multiple-phase four-class bulk ice scheme. Part I: Description. J. Atmos. Sci., 51, 249-280.

Ferrier, B. S., W.-K. Tao, and J. Simpson, 1995: A double-moment multiple-phase four-class bulk ice scheme. Part II: Simulations of convective storms in different large-scale environments and comparisons with other bulk parameterizations. J. Atmos. Sci., 52, 1001-1033.

Ferrier, B. S., J. Simpson and W.-K. Tao, 1996: Factors responsible for different precipitation efficiencies between midlatitude and tropical squall simulations. Mon. Wea. Rev.. 124, 2100-2125.

Finkele, K., J.M. Hacker, H. Kraus, and R.A.D Byron-Scott, 1995: A complete sea-breeze circulation cell derived from aircraft observations. Bound. Lay. Meterol., 73, 299 -- 317.

Fu, Q. and K.-N. Liou, 1993: Parameterization of the radiative properties of cirrus clouds. J. Atmos. Sci., 50, 2008-2025.

Fu, Q, S. K. Krueger, and K.-N. Liou, 1995: Interaction of radiation and convection in simulated tropical cloud clusters. J. Atmos. Sci., 52, 1310-1328.

Fu, Q., 1996: An accurate parameterization of the solar radiative properties of cirrus clouds for climate models. J. Climate, 9, 2058-2082. 
Fu, Q., K.-N. Liou, M. C. Cribb, T. P. Charlock, and A. Grossman, 1997: Multiple scattering parameterization in thermal infrared radiative transfer. J. Atmos. Sci., 54, 2799-2812.

GEWEX Cloud System Science Team, 1993: The GEWEX Cloud System Study (GCSS). Bull. Amer. Meteor. Soc., 74, 387-399.

Gray, W. M., and R. W. Jacobsen, 1977: Diurnal variation of deep cumulus convection. Mon. Wea. Rez', 105, 1171-1188.

Hallett, J. and Mossop, S. C., 1974: Production of secondary ice crystals during the riming process. Nature, 249, 26-28.

Henderson-Sellers, Z.-L. Yang and R. E. Dickinson, 1993: The project for intercomparison of land surface parameterization schemes. Bull. Amer. Meteor. Soc., 74, 1335-1349.

Henderson-Sellers, A. J. Polcher, P. K. Love, K. McGuffie, T. H. Chen, 1995: The project for intercomparison of land surface parameterization schemes (PILPS): Phases 2 and 3, Bull. Amer. Meteor. Soc., 76, 489-503.

Johnson, D., W.-K. Tao, J. Simpson, and C.-H. Sui, 2001: A study of the response of deep tropical clouds to large-scale processes, Part I: Model set-up strategy and comparison with observation, J. Atmos. Sci.. (submitted).

Jorgensen, D. P., T. J. Matejka, M. A. LeMone, 1995: Structure and momentum fluxes within a TOGA/COARE squall line system observed by airborne doppler radar. 21st Conf. Hurricanes and Tropical Meteor., Amer. Meteor. Soc., Miami, 579-581.

Jorgensen, D. P., M. A. LeMone, and S. B. Trier, 1997: Structure and evolution of the 22 February 1993 TOGA COARE squall line: Aircraft observations of precipitation, circulation, and surface fluxes. J. Atmos. Sci 125, 1961-1985.

Khain, A. P., and I. Sednev, 1996: Simulation of precipitation formation in the Eastern Mediterranean coastal zone using a spectral microphysics cloud ensemble model. Atmos. Res., 43, 77-110.

Khain, A. P. and M. Pinsky, 1997: Turbulence effects on the collision kernel, Part 2: Increase of swept volume of colliding drops. Quart. J. Roy. Meteor. Soc., 123, 1543-1560.

Khain A.P., A. Pokrovsky, and I. Sednev, 1999a: Some effects of cloud-aerosol interaction on cloud microphysics structure and precipitation formation: Numerical experiments with a spectral microphysics cloud ensemble model. Atmos. Res., 52, 195-220.

Khain A.P., Pinsky, M. B., M. Shapiro and A. Pokrovsky, 1999b: Graupel-drop collision efficiencies. J. Atmos. Sci. (in press).

Khain, A. P., M. Ovtchinnikov, M. Pinsky, A. Pokrovsky, and H. Krugliak, 2000: Notes on the stateof-the-art numerical modeling of cloud microphysics. Atmosph. Res., 55, 159-224. 
Kratz, D. P., M.-D. Chou, M. M.-H. Yan, and C.-H. Ho, 1998: Minor trace gas radiative forcing calculations using the k-distribution method with one-parameter scaling. J. Geophy. Res., 103, 31647-31656.

Kraus, E. B., 1963: The diurnal precipitation change over the sea. J. Atmos. Sci., 20, 546-551.

Kraus, E. B., and J. S. Turner, 1967: A one-dimensional model of the seasonal thermocline, II, The general theory and its consequences, Tellus, 19, 98-106.

Kuo, Y.-H., R. J. Reed and Y.-B. Liu, 1996: The ERICA IOP5 storm. Part III: Mesoscale cyclogenesis and precipitation parameterization. Mon. Wea. Rev., 124, 1409-1434.

Lang, S., W.-K. Tao, J. Simpson and B. Ferrier, 2001: Numerical modeling of convective-stratiform precipitation processes: Sensitivity to partition methods and numerical advection schemes, $J$. Applied Meteor. (submitted).

Lau, K. M., C. H. Sui and W.-K. Tao, 1993: A preliminary study of the tropical water cycle and its sensitivity to surface warming. Bull. Amer. Meteor. Soc., 74, 1313-1321.

Lau, K. M., C.-H. Sui, M.-D. Chou, and W.-K. Tao, 1994: An enquiry into the cirrus-cloud thermostat effect for tropical sea surface temperature. Geophys. Res. Lett., 21, 1157-1160.

LeMone, M. A., D. P. Jorgensen, S. Lewis, B. Smull, and T. Matejka, 1995: Boundary layer recovery in the stratiform region of mesoscale convective systems in TOGA COARE. 21st Conf. Hurricanes and Tropical Meteor., Amer. Meteor. Soc., Miami, 509-511.

Li, X., C.-H. Sui, D. Adamec and K.-M. Lau, 1998: Impacts of precipitation in the upper ocean in the western Pacific warm pool during TOGA-COARE. J. Geophys. Res. 103, C3, 5347-5359.

Li, X., C.-H. Sui, K.-M. Lau and D. Adamec, 2000: Effects of precipitation on ocean mixed-layer temperature and salinity as simulated in a 2-D coupled ocean-cloud resolving atmosphere model. I. Meteor. Soc. Japan., 78, 647-659.

Lin, Y.-L., R. D. Farley and H. D. Orville, 1983: Bulk parameterization of the snow field in a cloud model. J. Clim. Appl. Meteor., 22, 1065-1092.

Lin, X., and R. H. Johnson, 1996: Heating, moistening and rainfall over the western Pacific during TOGA COARE. J. Atmos. Sci., 53, 3367-3383.

Lindzen, R., 1990a: Some coolness concerning global warming. Bull. Amer. Meteor. Soc., 71, 288-299.

Lindzen, R., 1990b: Response to "Greenhouse warming and the tropical water budget". Bull. Amer. Meteor. Soc., 71, 1465-1467.

Liu, C., and M. W. Moncrieff, 1998: A numerical study of the diurnal cycle of tropical oceanic convection. J. Atmos. Sci. 55, 2329-2344.

Liu, W. T., K. B. Katsaros, and J. A. Businger, 1979: Bulk parameterization of the air-sea exchange of heat and water vapor including the molecular constraints at the interface. J. Atmos. Sci., 36, 17221735. 
Liu, Y., D.-L. Zhang, and M. K. Yau, 1999: A multiscale numerical study of Hurricane Andrew (1992). Part II: Kinematics and inner-core structures. Mon. Wea. Rev., 127, 2597-2616.

Lord, S. J., H. E. Willoughby and J. M. Piotrowicz, 1984: Role of a parameterized ice-phase microphysics in an axisymmetric, non-hydrostatic tropical cyclone model. J. Atmos. Sci., 41, 28362848.

Lynn, B.H., D. Rind, R. Avissar, 1995a: The importance of mesoscale circulations generated by subgrid-scale landscape-heterogeneities in general circulation models. I. Climate., 8, 191--205.

Lynn, B.H., F. Abramopoulos, and R. Avissar, 1995b: Using similarity theory to parameterize the mesoscale fluxes generated by landscape discontinuities in GCMs. J. Climate, 8, 932--951.

Lynn, B.H., W.-K. Tao, P.J. Wetzel, 1998: A study of landscape generated deep moist convection. Mon. Wea. Rev., 126, 928-942.

Lynn, B.H., and W.K. Tao, 2001: A Parameterization for the Triggering of Landscape Generated Moist Convection, Part II: zero order and first order closure. J. Atmos. Sci., (in press).

Lynn, B.H., W.K. Tao, and F. Abramopoulos, 2001a: A Parameterization for the Triggering of Landscape Generated Moist Convection, Part I: Analysis of high resolution model results. I. Atmos. Sci., (in press).

Lynn, B. H., D. Stauffer, P. Wetzel, W.-K. Tao, P. Alpert, N. Perlin, R. D. Baker, R. Munoz, A. Boone, and Y. Jia, 2001b: A simulation of a Florida sea-breeze using a mesoscale model (MM5) with a new turbulent kinetic energy (TKE) atmospheric boundary layer model and sophisticated land surface model (PLACE), Mon. Wea. Rev., (in press).

Malkus, J. S., 1962: Ideas and observations on progress in the study of the seas. The Sea, vol.1, Physical Oceanography. Ed. M. N. Hill, John Wiley \& Sons, New York, 88-294.

McCumber, M., W.-K. Tao, J. Simpson, R. Penc, and S.-T. Soong, 1991: Comparison of ice-phase microphysical parameterization schemes using numerical simulations of convection. J. Appl. Meteor., 30, 985-1004.

Moncrieff, M. W., S. K. Krueger, D. Gregory, J.-L. Redelsperger and W.-K. Tao, 1997: GEWEX Cloud System Study (GCSS) Working Group 4: Precipitating convective cloud systems. Bull. Amer. Meteor. Soc., 78, 831-845.

Parsons, D., W. Dabberdt, H. Cole, T. Hock, C. Martin, A. Barret, E. Miller, M. Spoward, M. Howard, W.Ecklund, D.Carter, K.Gage, and J. Wilson, 1994: The integrated sounding system: Description and preliminary observations from TOGA COARE. Bull. American Meteorol. Soc., 75, 553-567.

Pickering, K. E., J. R. Scala, A. M. Thompson, W.-K. Tao, and J. Simpson, 1992: A regional estimate of convective transport of CO from biomass burning. Geophys. Res. Lett., 19, 289-292.

Pielke, R.A., G.A. Dalu, J.S. Snook, T.J. Lee, and T.G.F. Kittel, 1991: Nonlinear influence of mesoscale land use on weather and climate. J. Climate, 4, 1053--1069. 
Pinsky, M., and A. Khain, 1998: Some effects of cloud turbulence on water-ice and ice-ice collisions, Atmos. Res., 47-48, 69-86.

Pinsky, M. B., A. P. Khain, D. Rosenfeld, and A. Pokrovsky, 1998: Comparison of collision velocity differences of drops and graupel particles in a very turbulent cloud. Atmos. Res., 49, 99-113.

Pinsky, M., A. Khain, and M. Shapiro, 1999: Collisions of small drops in a turbulent flow. Pt.1: Collision efficiency: problem formulation and preliminary results. J. Atmos. Sci. , 56, 2585-2600.

Pinsky, M., A. P. Khain, and M. Shapiro, 2000a: Stochastic effects on cloud droplet hydrodynamic interaction in a turbulent flow. Atmos. Res., 53, 131-169.

Pinsky, M., A. Khain, and M. Shapiro and A. Pokrovsky, 2000b: Collision efficiencies of drops in a wide range of Reynolds numbers: effects of pressure. J. Atmos. Sci. (in press).

Prasad, N, H.-Y. M. Yeh, R. F. Adler and W.-K. Tao, 1995: Infrared and microwave simulations of an intense convective system and comparison with aircraft observations. J. Appl. Meteor., 34, 153174.

Pruppacher, H. R., 1995: A new look at homogeneous ice nucleation in supercooled water drops. J. Atmos. Sci., 52, 1924-1933.

Pruppacher, H. R., and J. D. Klett, 1997: Microphysics of clouds and precipitation. 2-nd edition, Oxford Press, $954 \mathrm{p}$.

Ramaswamy, V., and V. Ramanathan, 1989: Solar absorption by cirrus clouds and the maintance of the tropical upper troposphere thermal structure. J. Atmos. Sci., 46, 2293-2310.

Randall, D. A., Harshvardhan, and D. A., Dazlich, 1991: Diurnal variability of the hydrologic cycle in a general circulation model. J. Atmos. Sci., 48, 40-62.

Roll, H. U., 1965: Physics of the Marine Atmosphere. Academic Press, New York. 426 pp.

Rosenfeld, D. 2000: Suppression of rain and snow by urban and industrial air pollution. Science, 287, (5459), 1793-1796.

Rutledge, S.A., and P.V. Hobbs, 1984: The mesoscale and microscale structure and organization of clouds and precipitation in mid-latitude clouds. Part XII: A diagnostic modeling study of precipitation development in narrow cold frontal rainbands. J. Atmos. Sci., 41, 2949-2972.

Scala, J. R., M. Garstang, W.-K. Tao, K. E. Pickering, A. M. Thompson, J. Simpson, V. W. J. H. Kirchoff, E. V. Browell, G. W. Saschse, A. L. Torres, G. L. Gregory, R. A. Rasmussen, and M. A. K. Khalil, 1990: Cloud draft structure and trace gas transport. J Geophys. Res., 95, 17015-17030.

Segal, M., R. W. Arritt, and C. Clark, 1995: Scaling evaluation of the effect of surface characteristics on potential for deep convection over uniform terrain. Mon. Wea. Rev., 123, 383-400.

Simpson, J., R. F. Adler, and G. R. North, 1988: A proposed tropical rainfall measuring mission (TRMM) satellite. Bull. Amer. Meteor. Soc., 69, 278-295. 
Simpson, J., and W.-K. Tao, 1993: The Goddard Cumulus Ensemble Model. Part II: Applications for studying cloud precipitating processes and for NASA TRMM. Terrestrial, Atmospheric and Oceanic Sciences, 4, 73-116.

Simpson, J., C. Kummerow, W.-K. Tao, and R. Adler, 1996: On the Tropical Rainfall Measuring Mission (TRMM), Meteor. and Atmos. Phys. , 60, 19-36, 1996.

Smolarkiewicz, P.K., 1983: A simple positive definite advection scheme with small implicit diffusion. Mon. Wea. Rev., 111, 479-486.

Smolarkiewicz, P.K., 1984: A fully multidimensional positive definite advection transport algorithm with small implicit diffusion. J. Comput. Phys., 54, 325-362.

Smolarkiewicz, P.K., and W.W. Grabowski, 1990: The multidimensional positive advection transport algorithm: nonoscillatory option. J. Comput. Phys., 86, 355-375.

Soong, S.-T., and Y. Ogura, 1973: A comparison between axisymmetric and slab-symmetric cumulus cloud models. J. Atmos. Sci, 30, 879-893.

Soong, S.-T., and Y. Ogura, 1980: Response of trade wind cumuli to large-scale processes. J. Atmos. Sci., 37, 2035-2050.

Soong, S.-T., and W.-K. Tao, 1980: Response of deep tropical clouds to mesoscale processes. J. Atmos. Sci., 37 2016-2036.

Soong, S.-T., and W.-K. Tao, 1984: A numerical study of the vertical transport of momentum in a tropical rainband. J. Atmos. Sci., 41,1049-1061.

Stephens, G. L., 1978, Radiative profiles in extended water clouds. Part II: Parameterization schemes. J. Atmos. Sci., 35, 2123-2132.

Stephens, G. L., 1984: The parameterization of radiation for numerical weather prediction and climate models. Mon. Wea. Rev, 112, 826-867.

Sui, C. H., K. M. Lau, W.-K. Tao, and J. Simpson, 1994: The tropical water and energy cycles in a cumulus ensemble model. Part I: Equilibrium climate. J. Atmos. Sci., 51, 711-728.

Sui, C.-H., X. Li, K.-M. Lau, and D. Adamec, 1997a: Multi-scale air-sea interaction during TOGA COARE. Mon. Wea. Rev. 125, 448-462.

Sui, C.-H., K.-M. Lau, Y. Takayabu, and D. Short, 1997b: Diurnal variations in tropical oceanic cumulus convection during TOGA COARE. J. Atmos. Sci. 54, 637-655

Sui, C. H., K. M. Lau, and X. Li, 1998: Convective-radiative interaction in simulated diurnal variations of tropical cumulus ensemble. J. Atmos. Sci., 55, 2345-2357.

Szoke, E. J. and E. J. Zipser, 1986: A radar study of convective cells in mesoscale systems in GATE. Part II. Life cycles of convective cells. J. Atmos. Sci., 43, 199-218.

Tao, W.-K., 1978: A numerical simulation of deep convection in the tropics, M.S. Thesis, Department of Atmospheric Science, University of Illinois, 66 pp.. 
Tao, W.-K., 1983: A numerical study of the structure and vertical transport properties of a tropical convective system. Ph.D. Dissertation, Department of Atmospheric Science, University of Illinois, $228 \mathrm{pp}$.

Tao, W.-K., and J. Simpson, 1984: Cloud interactions and merging: Numerical simulations. J. Atmos. Sci., 41, 2901-2917.

Tao, W.-K., and S.-T. Soong, 1986: A study of the response of deep tropical clouds to mesoscale processes: Three-dimensional numerical experiments. J. Atmos. Sci., 43, 2653-2676.

Tao, W.-K., J. Simpson, and S.-T. Soong, 1987: Statistical properties of a cloud ensemble: A numerical study. J. Atmos. Sci., 44, 3175-3187.

Tao, W.-K., and J. Simpson, 1989a: A further study of cumulus interaction and mergers: Threedimensional simulations with trajectory analyses. J. Atmos. Sci., 46, 2974-3004.

Tao, W.-K., and J. Simpson, 1989b: Modeling study of a tropical squall-type convective line. J. Atmos. Sci., 46, 177-202.

Tao, W.-K., J. Simpson and M. McCumber, 1989: An ice-water saturation adjustment. Mon. Wea. Rev., 117, 231-235.

Tao, W.-K., J. Simpson, S. Lang, M. McCumber, R. Adler and R. Penc, 1990: An algorithm to estimate the heating budget from vertical hydrometeor profiles. J. Appl. Meteor., 29, 1232-1244.

Tao, W.-K., J. Simpson, and S.-T. Soong, 1991: Numerical simulation of a sub-tropical squall line over Taiwan Strait. Mon. Wea. Rev., 119, 2699-2723.

Tao, W.-K., J. Simpson, C.-H. Sui, B. Ferrier, S. Lang, J. Scala, M.-D. Chou, and K. Pickering, 1993a: Heating, moisture and water budgets of tropical and mid-latitude squall lines: Comparisons and sensitivity to longwave radiation. J. Atmos. Sci., 50, 673-690.

Tao, W.-K., J. Simpson, S. Lang, J. Simpson and R. Adler, 1993b: Retrieval Algorithms for estimating the vertical profiles of latent heat release: Their applications for TRMM. J. Meteor. Soc. Japan, 71, 685-700.

Tao, W.-K., and J. Simpson, 1993: The Goddard Cumulus Ensemble Model. Part I: Model description. Terrestrial, Atmospheric and Oceanic Sciences, 4, 19-54.

Tao, W.-K., J. Scala, B. Ferrier, and J. Simpson, 1995: The effects of melting processes on the development of a tropical and a mid-latitudes squall line. J. Atmos. Sci., 52, 1934-1948.

Tao, W.-K., 1995: Interaction of parameterized convection and explicit stratiform cloud microphysics. WMO/WCRP-90, Cloud Microphysics Parameterizations in Global Atmospheric General Circulation Models, Ed. D. Randall, 199-210.

Tao, W.-K., S. Lang, J. Simpson, C.-H. Sui and B. Ferrier and M.-D. Chou, 1996: Mechanisms of Cloudradiation interaction in the tropics and midlatitudes. J. Atmos. Sci. 53, 2624-2651. 
Tao, W.-K., J. Simpson and B. Ferrier, 1997: Cloud Resolving Model Simulations of Mesoscale Convective Systems, New Insights and Approaches to Convective Parameterization, Ed. D. Gregory, 77-112.

Tao, W.-K., J. Simpson, C.-H. Sui, C.-L. Shie, B. Zhou, K. M. Lau, and, M. Moncrieff, 1999: On equilibrium states simulated by Cloud-Resolving Models, J. Atmos. Sci., 56, 3128-3139.

Tao, W.-K., S. Lang, J. Simpson, W. S. Olson, D. Johnson, B. Ferrier, C. Kummerow and R. Adler, 2000: Vertical profiles of latent heat release and their retrieval in TOGA COARE convective systems using a cloud resolving model, SSM/I and radar data, J. Meteor. Soc. Japan, 78, 333-355.

Tao, W.-K., S. Lang, W. S. Olson, S. Yang, R. Meneghini, J. Simpson, E. Smith, C. Kummerow, E. Smith and J. Halverson, 2001a: Retrieved Vertical Profiles of Latent Heat Release Using TRMM Products for February 1998, J. Appl. Meteor. (in press).

Tao, W.-K., C.-L. Shie and J. Simpson, 2001b: Comments on The sensitivity study of radiativeconvective equilibrium in the Tropics with a convective resolving model, J. Atmos. Sci. (in press).

Tao, W.-K., 2001: Goddard Cumulus Ensemble (GCE) model: Application for understanding precipitation processes, AMS Meteorological Monographs - Symposium on Cloud Systems, Hurricanes and TRMM, (accepted).

Tao, W.-K., C.-S. Chen, Y. Jia, S. Lang, R. D. Baker, P. Wetzel and W. K.-M. Lau, 2001c: A study of heavy precipitation events in Taiwan during 10-13 August 1994: Part II: Regional Scale Model Simulations. J. Meteor. Soc. Japan (submitted).

Thompson, A. M., W.-K. Tao, K. E. Pickering, J. Scala, and J. Simpson, 1997: Tropical deep convection and ozone formation, Bull. Amer. Meteor. Soc., 78, 1043-1054.

Vali, G., 1975: Remarks on the mechanism of atmospheric ice nucleation. Proc. 8th Int. Conf. on Nucleation, Leningrad, 23-29, Sept. I.I. Gaivoronski Ed., Gidrometeoizdat, 265-269.

Wang, Y., W.-K. Tao, and J. Simpson, 1996: The impact of ocean surface fluxes on a TOGA COARE convective system. Mon. Wea. Rev,, 124, 2753-2763.

Wang, Y., W.-K. Tao, J. Simpson and S. Lang, 2001: The sensitivity of tropical squall lines (GATE and TOGA COARE) to surface fluxes: Cloud resolving model simulations, Q. J. R. Met. Soc., (accepted).

Wetzel, P. J., and A. Boone,1995: A parameterization for land-atmosphere-cloud exchange (PLACE): Documentation and testing of a detailed process model of the partly cloudy boundary layer over heterogeneous land. J. of Climate, 8, 1810-1837.

Yang, M.-J., F.-C. Chien and M.-D. Cheng, 2000: Precipitation parameterization in a simulated MeiYu front. Terrestrial, Atmospheric and Oceanic Sciences (TAO), 11, 393-422.

Yeh, H.-Y., M. N. Prasad, R. Meneghini, W.-K. Tao and R.F. Adler, 1995: Model-based simulation of TRMM spaceborne radar observations. J. Appl Meteor., 34, 175-197. 
Young, G. S., D. V. Ledvina, and C. W. Fairall, 1992: Influence of precipitating convection on the surface energy budget observed during a tropical ocean global atmosphere pilot cruise in the tropical western pacific ocean. J. Geophy. Res., 97, 9595-9603. 


\section{FIGURE CAPTIONS}

Fig. 1 Schematic diagram showing the characteristics of the GCE model. Arrows with solid lines indicate a two-way interaction between different physical processes and arrows with dashed lines indicate a one-way interaction. (SCM - Single Column Model)

Fig. 2 Three-class ice scheme implemented in the Goddard Cumulus Ensemble (GCE) model (after Lin et al. 1983). Note that the PSFC term was modified by Braun et al. (2001).

Fig. 3 Schematic representation of the PLACE Model. The calculation of each specific physical parameters is listed (equation) in Wetzel and Boone (1995). (See text for more details.)

Fig. 4 Suface rainfall rate $(\mathrm{mm} / \mathrm{h})$ simulated by the 3D GCE model for a TOGA COARE squall system. (a), (b) and (c) are for the $4 \mathrm{ICE}$ scheme at 4,6 and $8 \mathrm{~h}$, respectively, into the model simulation. (d), (e) and (f) are the same as (a), (b) and (c) except for the 3ICE scheme. The model domain consisted of $172 \times 142$ grid points in the horizontal $x$ and $y$ directions and the lateral boundaries were open. The horizontal grid resolution was $2 \mathrm{~km}$. The vertical direction had 34 grid points up to $23.9 \mathrm{~km}$ stretched from $42.5 \mathrm{~m}$ at the lowest grid point to $1196 \mathrm{~m}$ at the top grid.

Fig. 5 As Fig. 4 expect for GATE squall system.

Fig. 6 Vertical profiles of time and domain averaged hydrometeor (cloud water, rain, cloud ice, snow, graupel and hail) content $(\mathrm{g} / \mathrm{kg}$ ) over $9 \mathrm{~h}$ of 3D GCE model simulations of TOGA COARE and GATE squall systems using 3ICE and 4ICE schemes. (a) and (b) are for the TOGA COARE case using 3ICE and 4ICE schemes, respectively. (c) and (d) are the same as (a) and (b) except for the GATE case. Note that the abscissa used in the 4ICE and 3ICE schemes is different.

Fig. 7 Vertical cross-sections of cloud water content $(\mathrm{g} / \mathrm{kg}) 720$ minutes into 2D GCE model simulations of a midlatitude squall line (PRESTORM) using three different saturation adjustment techniques: (a) Tao et al. (1989), (b) Lord et al. (1984), and (c) the new saturation technique.

Fig. 8 Vertical profiles of time and domain averaged cloud water and cloud ice content $(\mathrm{g} / \mathrm{kg})$ over 720 minutes of 2D GCE model simulations of a midlatitude squall line (PRESTORM) 
using three different saturation adjustment techniques: (a) Tao et al. (1989), (b) Lord et al. (1984), and (c) the new saturation technique.

Fig. 9 Vertical cross-sections of time averaged (a, c) snow mixing ratio and $(b, d)$ cloud ice mixing ratio. Cross-sections were obtained by averaging fields between hours 5-6 of simulations using output at $10 \mathrm{~min}$ intervals. Panels $\mathrm{a}$ and $\mathrm{b}$ correspond to a simulation using the original formulations of PSFI, while panels $\mathrm{c}$ and $\mathrm{d}$ correspond to a simulation using a new formulation of PSFI (Braun et al. 2001). The contour intervals are $0.1 \mathrm{~g} \mathrm{~kg}^{-1}$ starting at 0.01 $\mathrm{g} \mathrm{kg}^{-1}$ for snow and $0.025 \mathrm{~g} \mathrm{~kg}^{-1}$ starting at $0.001 \mathrm{~g} \mathrm{~kg}^{-1}$ for cloud ice.

Fig. 10 Combined cloud- and rain-water mixing ratio using (a) low and (b) high-condensation nuclei concentration at 34 minutes. A computational domain size of $128 \times 20 \mathrm{~km}$ is used with a horizontal grid spacing of $1000 \mathrm{~m}$ and vertical grid spacing ranging from $80 \mathrm{~m}$ just above the surface, to $1000 \mathrm{~m}$ at the top of the domain. A TOGA-COARE IFA sounding taken prior to a westerly-wind burst is applied initially, and observed large-scale "forcing" of horizontal momentum, and temperature and moisture advection are applied to the model simulation.

Fig. 11 Normalized droplet size spectrum using (a) low and (b) high CCN at 34 minutes. Shown are the 33 bins used in each simulation with each increasing bin size set to twice the mass of the previous bin.

Fig. 12 Vertical mean profiles of cloud and rain water mixing ratios for the droplet fields shown in Fig. 10 for the low (surface $C C N=100$ ) and high (surface $C C N=1200$ ) $C C N$ experiments. The low $\mathrm{CCN}$ case produces approximately twice the rain water mass, but only half the cloud water mass when compared to the high CCN case. The low CCN cloud is a more efficient precipitation producer as depicted by the greater rain mass at the surface for this case.

Fig. 13 Schematic diagram demonstrating the effects by different cloud-radiation mechanisms (cloud-top cooling and cloud-base warming - alters the thermal stratification of the stratiform cloud layer; differential cooling between clear and cloudy regions - enhances dynamic convergence into the cloud system; and the large-scale radiative cooling destabilizes the large-scale environment).

Fig. 14 Diurnal composite of GCE model domain averaged daily rain rate $\left(\mathrm{mm} \mathrm{h}^{-1}\right)$. The solid lines denote the run with constant sea surface temperature (SST $-29.2^{\circ} \mathrm{C}$ ) and 
explicit/diurnal cloud-radiation interaction. The short-dashed lines denote the run with diurnal SST variation $\left(1{ }^{\circ} \mathrm{C}\right.$ difference between the maximum and minimum) and explicit/diurnal cloud-radiation interaction. The long-dashed lines are for the run without SST diurnal variation and no diurnal variation in radiation. A GCE model domain size of $768 \mathrm{~km}$ was used with a horizontal grid spacing of $1500 \mathrm{~m}$. The vertical direction had 33 grid points up to $22.5 \mathrm{~km}$ stretched from $100 \mathrm{~m}$ at the lowest grid point to $1028 \mathrm{~m}$ at the top grid. The initial thermodynamic conditions represented the disturbed periods during the TOGA COARE Intensive Observation Period (IOP) (upper-air soundings representing the disturbed periods were averaged). The large-scale vertical velocity for the same disturbed periods was also imposed into the GCE model.

Fig. 15 Diurnal composite of horizontal mean relative humidity $(\%)$ from the daily mean values obtained from a 12-day simulation. (a) is for the run that allowed for the diurnal variation of radiative processes (Run 1 ) and (b) is for the run did not allow for the diurnal variation of radiative processes (Run 3 ).

Fig. 16 Time sequence of the GCE model estimated domain mean surface rainfall rate $\left(\mathrm{mm} \mathrm{h}^{-1}\right)$ for (a) a run where the horizontal momentum was relaxed to its initial value (containing strong vertical shear) and (b) a run where the horizontal wind was nudged to time-varying observed values. This type of CRM diagnostic and graphical presentation has been very popular and was first presented in Tao and Simpson (1984).

Fig. 17 Patch size versus total accumulation of rainfall for 28 experiments with seven different patches of dry and wet soil and four background wind profiles. The solid line is a spline interpolation of the data points, while the vertical bars represent one standard deviation. The experimental domain size was $512 \mathrm{~km}$ in the horizontal (with $500 \mathrm{~m}$ horizontal grid resolution). The vertical resolution varied from $20 \mathrm{~m}$ at the surface to $500 \mathrm{~m}$ near the tropopause. Each simulation was run for 16 hours with a time step of 5 seconds.

Fig. 18 Spatial and time distribution of convective available potential energy (CAPE) obtained from the coupled GCE-PLACE atmosphere-land surface model. The dry patch was located between 128 and $384 \mathrm{~km}$.

Fig. 19 Vertical west-to-east cross-section of mesoscale perturbation fields obtained at 1 PM. Note, the derived mesoscale perturbations were independent of $y$, or the north-to-south direction, since the data were averaged over the range of $y$ values. The dry patch was 
located from 32 to $96 \mathrm{~km}$. The experimental domain had a $250 \times 250 \mathrm{~m}^{2}$ horizontal grid resolution with periodic lateral boundary conditions and a stretched vertical coordinate. Each simulation was run for 15 hours with a time step of 5 seconds. The total domain size was 512 grid elements in the west-to-east direction and 32 grid-elements in the north-tosouth $(y)$ direction.

Fig. 20 Cross-sectional plots of rainfall versus time obtained in (a) the run with large patch sizes and no background wind, and (b) the run with several small patch sizes. (c) and (d) are the same as (a) and (b) except that the observed (large background) wind is included.

Fig. 21 Heterogeneous soil moisture initial conditions from an offline PLACE calculation. The total domain spans $400 \mathrm{~km}$ in the east-west direction (resolution $\sim 3.1 \mathrm{~km}$ ) with the interior $200 \mathrm{~km}$ consisting of land and the other $100 \mathrm{~km}$ on each side consisting of ocean. The north-south horizontal extent is $300 \mathrm{~km}$ (resolution $\sim 2.5 \mathrm{~km}$ ). The vertical resolution varies from $80 \mathrm{~m}$ at the surface to $1.2 \mathrm{~km}$ near the tropopause. The lateral boundaries are periodic.

Fig. 22 Peak rain rate $\left(\mathrm{mm} \mathrm{h}^{-1}\right)$ vs. local time. Solid lines are for Case A (heterogeneous soil moisture distribution) and dashed lines are for Case B (homogeneous soil moisture distribution).

Fig. 23 (a) Surface rain rate and (b) surface latent heat flux at 6 hours into the simulation using the TOGA COARE flux algorithm. (c) and (d) are the same as (a) and (b) except a simple bulk aerodynamic method is used. The GCE model domain consisted of $172 \times 142$ grid points in the horizontal $x$ and $y$ directions. The horizontal grid resolution was $2 \mathrm{~km}$.

Fig. 24 Time evolution of horizontal mean mixed layer temperature $\left({ }^{\circ} \mathrm{C}\right)$. (a) is for the period December 10-17, 1992 (Episode 1), (b) for period December 19-27, 1992 (Episode 2) and (c) for period February 9-13, 1993 (Episode 3). Solid lines denote the GCE-OML simulated SST and dashed lines the observed SST. The GCE-OML model domain size was $512 \mathrm{~km}$, with a horizontal grid spacing of $1000 \mathrm{~m}$. The vertical direction had 43 grid points up to $23.5 \mathrm{~km}$ stretched from $40 \mathrm{~m}$ at the lowest grid point to $1028 \mathrm{~m}$ at the top grid for the GCE model.

Fig. 25 Same as Fig. 24 except for the mixed layer depth (m). Solid lines denote the GCE-OML simulated mixed layer depth. 
Fig. 26 Same as Fig. 24 except for the 3-m salinity (PSU - practical salinity unit). Solid lines denote the GCE-OML simulated salinity and dashed lines the observed salinity . 


\section{TABLES}

Table 1 Applications of the Goddard Cumulus Ensemble (GCE) (After Tao, 2001). Specific topics and their respective GCE model characteristics, major results and references are shown.

Table 2 The microphysical schemes in the Goddard Cumulus Ensemble (GCE) Model.

Table 3 The major differences between the three class ice (3ICE) scheme and the four-class ice (4ICE) scheme.

Table 4 A sketch of microphysical processes taken into account in the spectralbin microphysical scheme.

Table 5 Interaction between hydrometeors in the spectral-bin microphysical scheme.

Table 6 Initial environmental conditions expressed in terms of CAPE, precipitable water, sea surface temperature (SST), surface air temperature, water vapor and wind for the TOGA COARE and GATE squall cases.

Table 7 Surface rainfall amounts ( $\mathrm{mm}$ ) accumulated over 9 hours for GCE simulated TOGA COARE and GATE squall systems using the 3ICE and 4ICE schemes. The percentage of rainfall that was stratiform is also given.

Table 8 Comparison of the sensible and latent heat fluxes simulated with the TOGA COARE flux algorithm and from observations. Disturbed (undisturbed) refers to the convective (cloud-free) areas. For the $2 \mathrm{D}$ model, a total of 1024 grid points was used in the horizontal with $750 \mathrm{~m}$ resolution. The resolution for the lowest vertical grid point was $85 \mathrm{~m}$ and $40 \mathrm{~m}$, in the 3D and 2D model, respectively. 

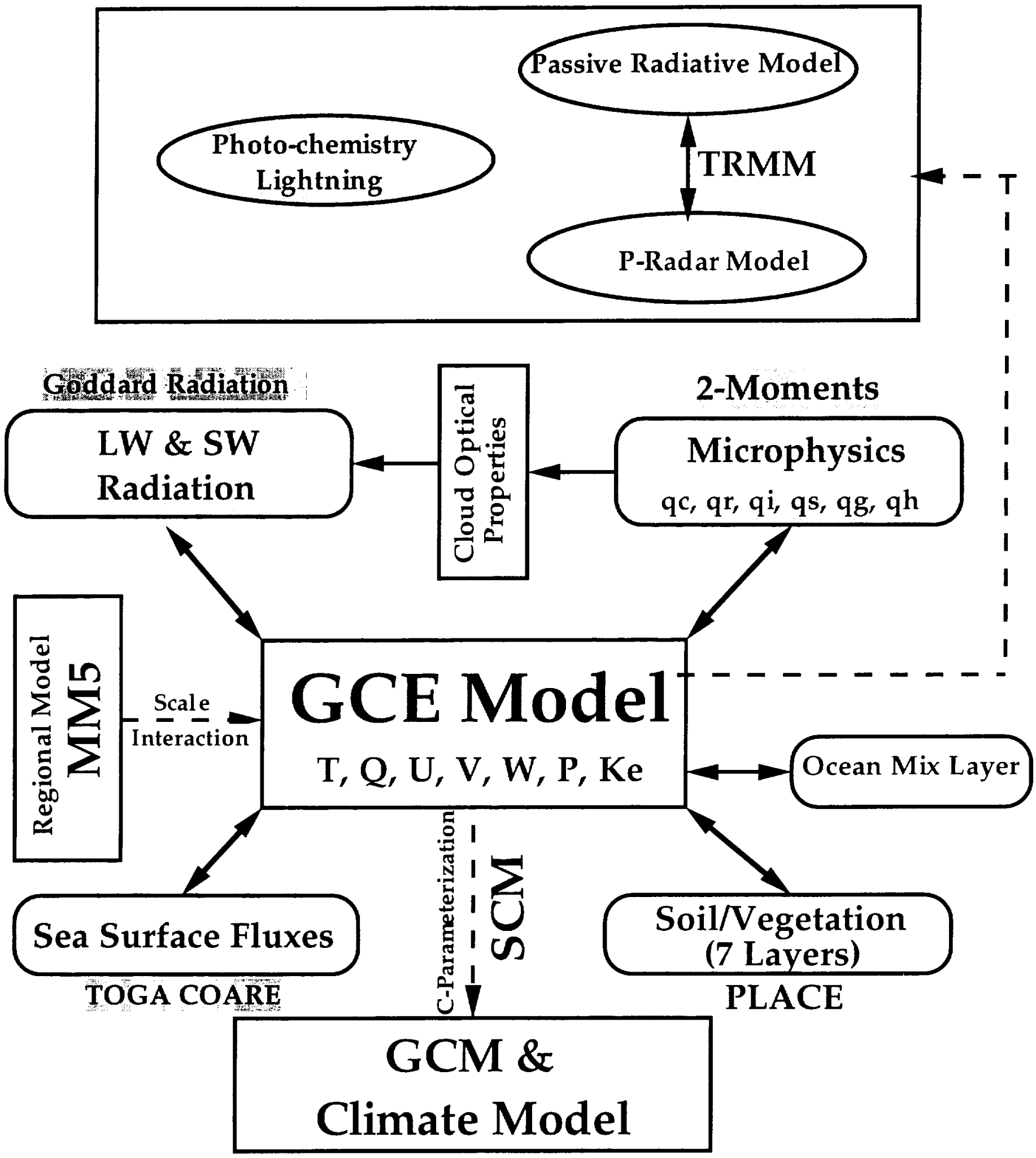

Fig. 1 




Fig. 2 


\section{Parameterization fcr Land-Armusphere-Cloud Exchange (PLACE): Model Schematic}

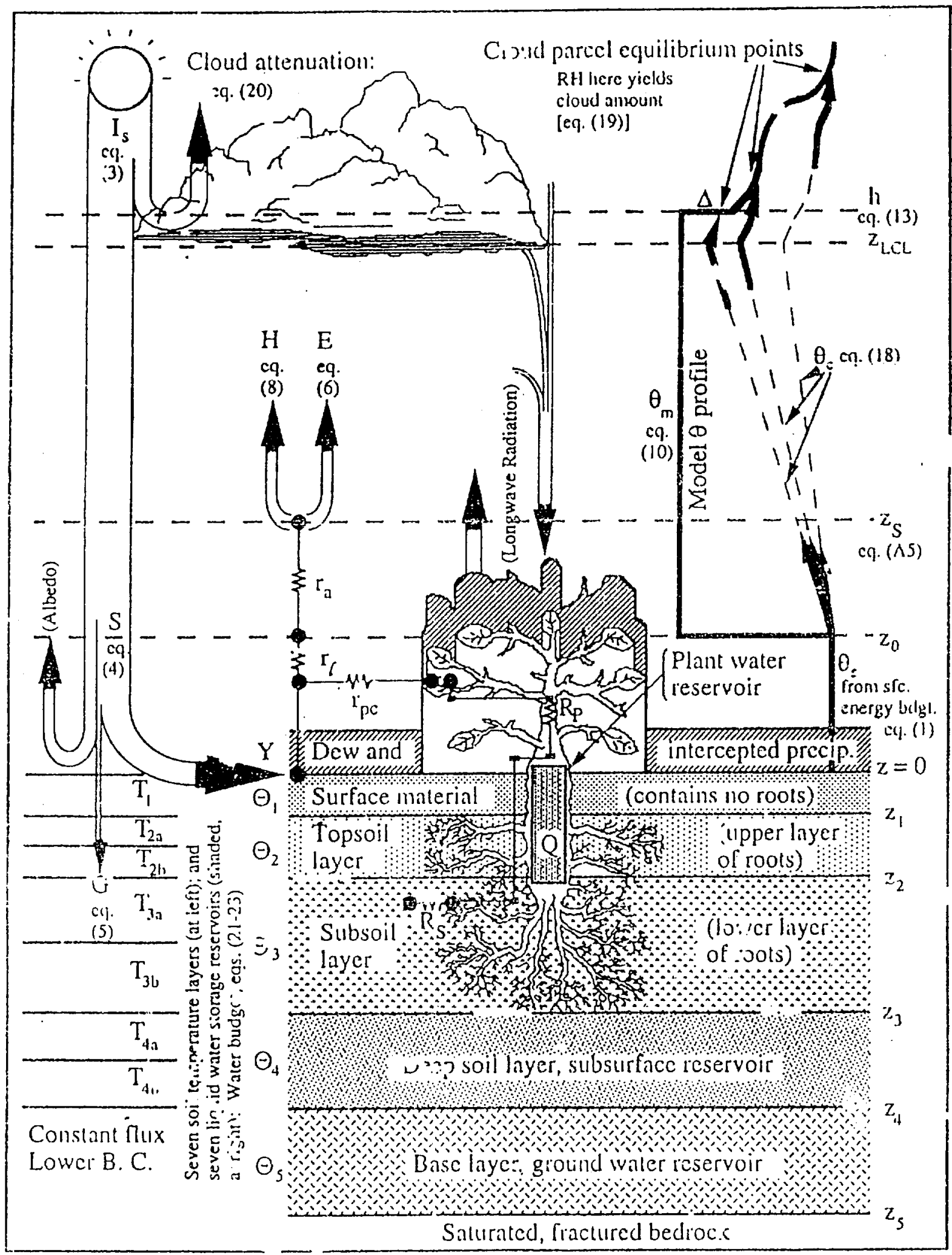



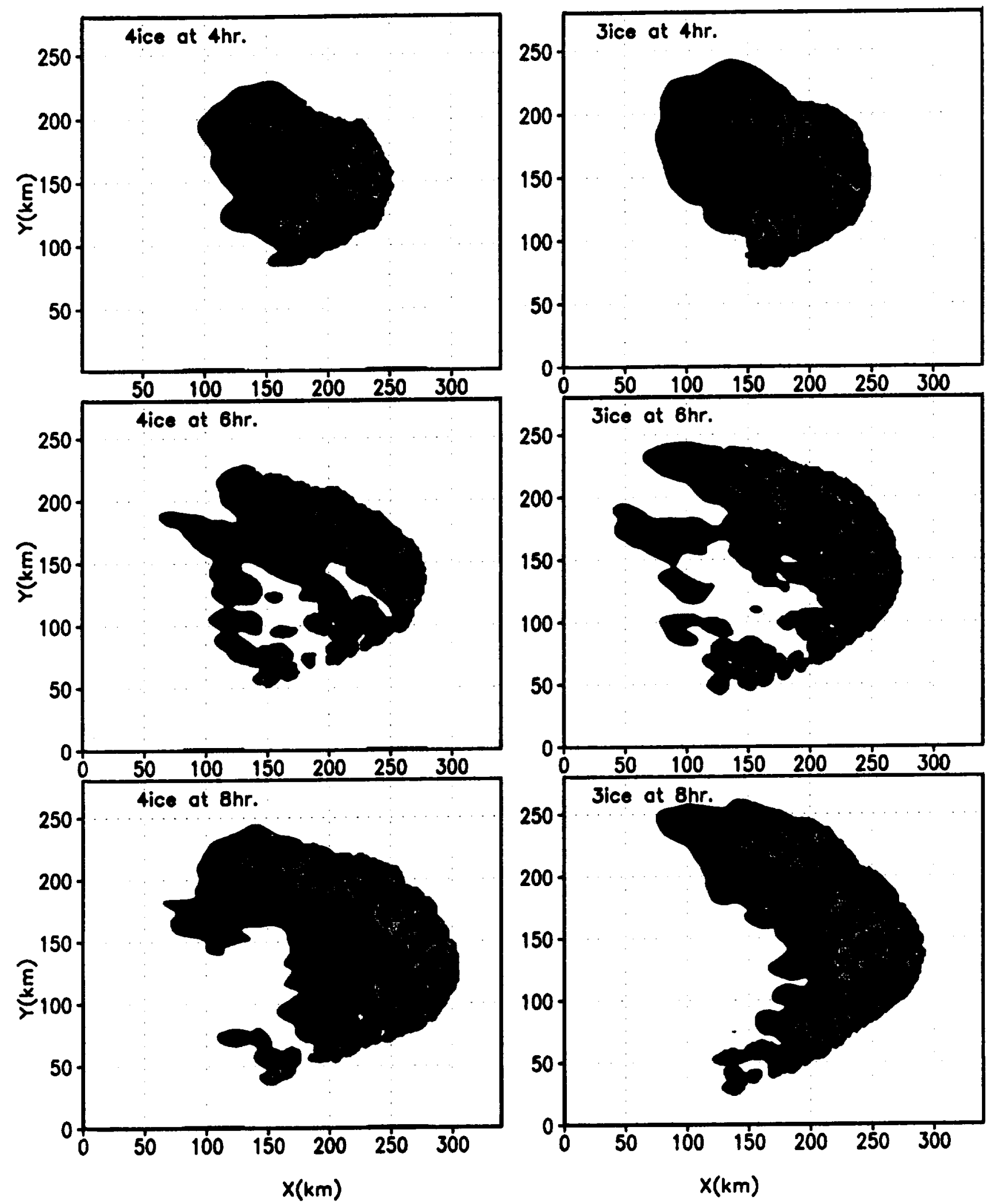

TOGA COARE Surface rainfall rate $(\mathrm{mm} / \mathrm{hr})$

\begin{tabular}{llllllllll}
\hline 0.01 & 0.5 & 1 & 5 & 10 & 15 & 20 & 25 & 30 & \\
\hline & & & & & & & & & Fig. 4
\end{tabular}





GATE Surface rainfall rate $(\mathrm{mm} / \mathrm{hr})$

\begin{tabular}{llllllllllll}
\hline 0.01 & 0.5 & 1 & 5 & 10 & 15 & 20 & 25 & 30 & \\
\hline & & & & & & & & & Fig. 5
\end{tabular}





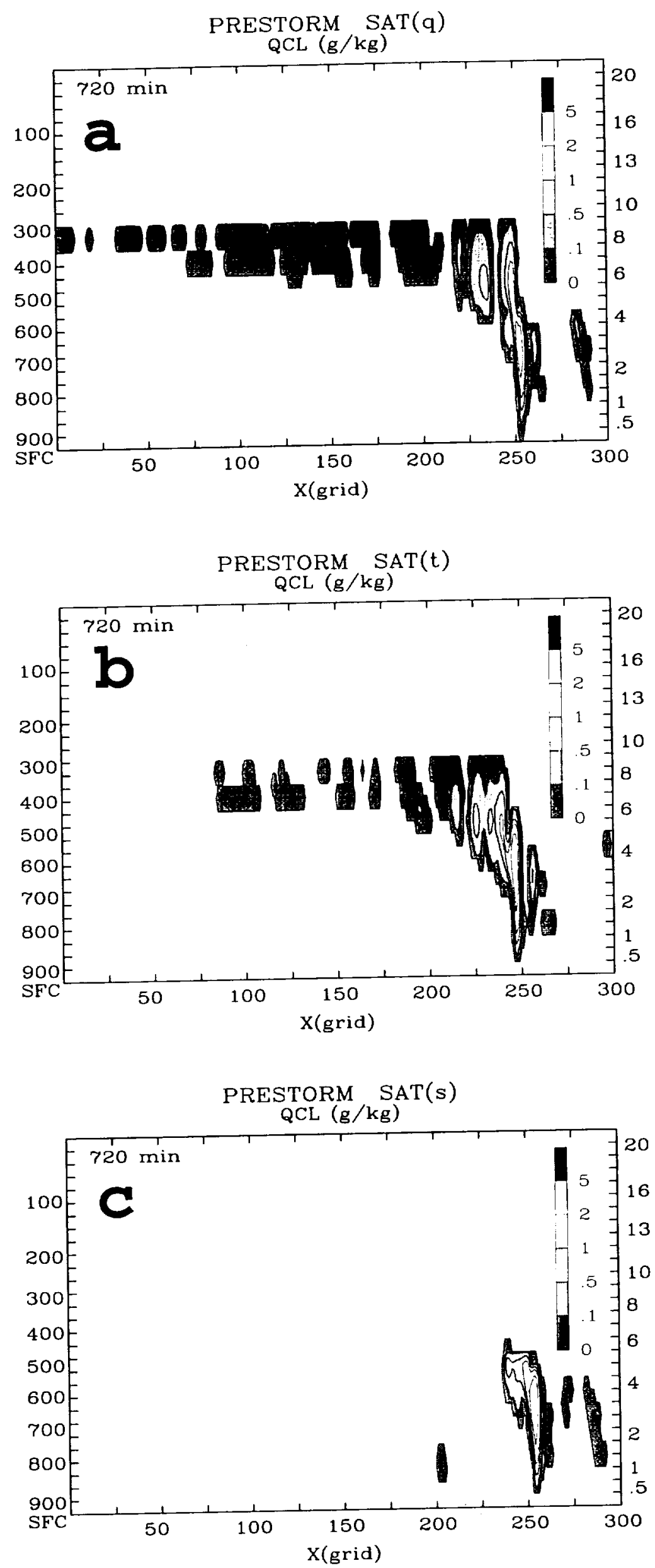

Fig. 7 

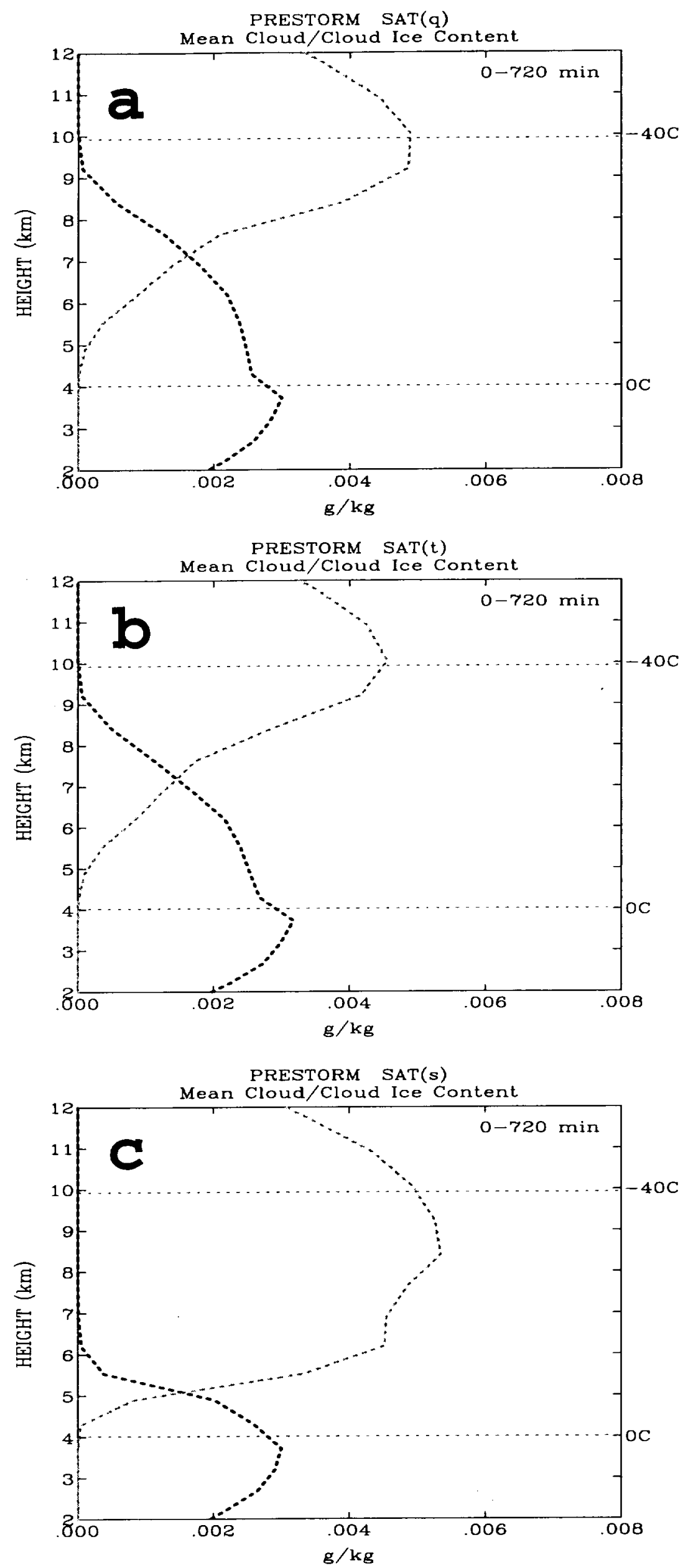

Fig. 8 




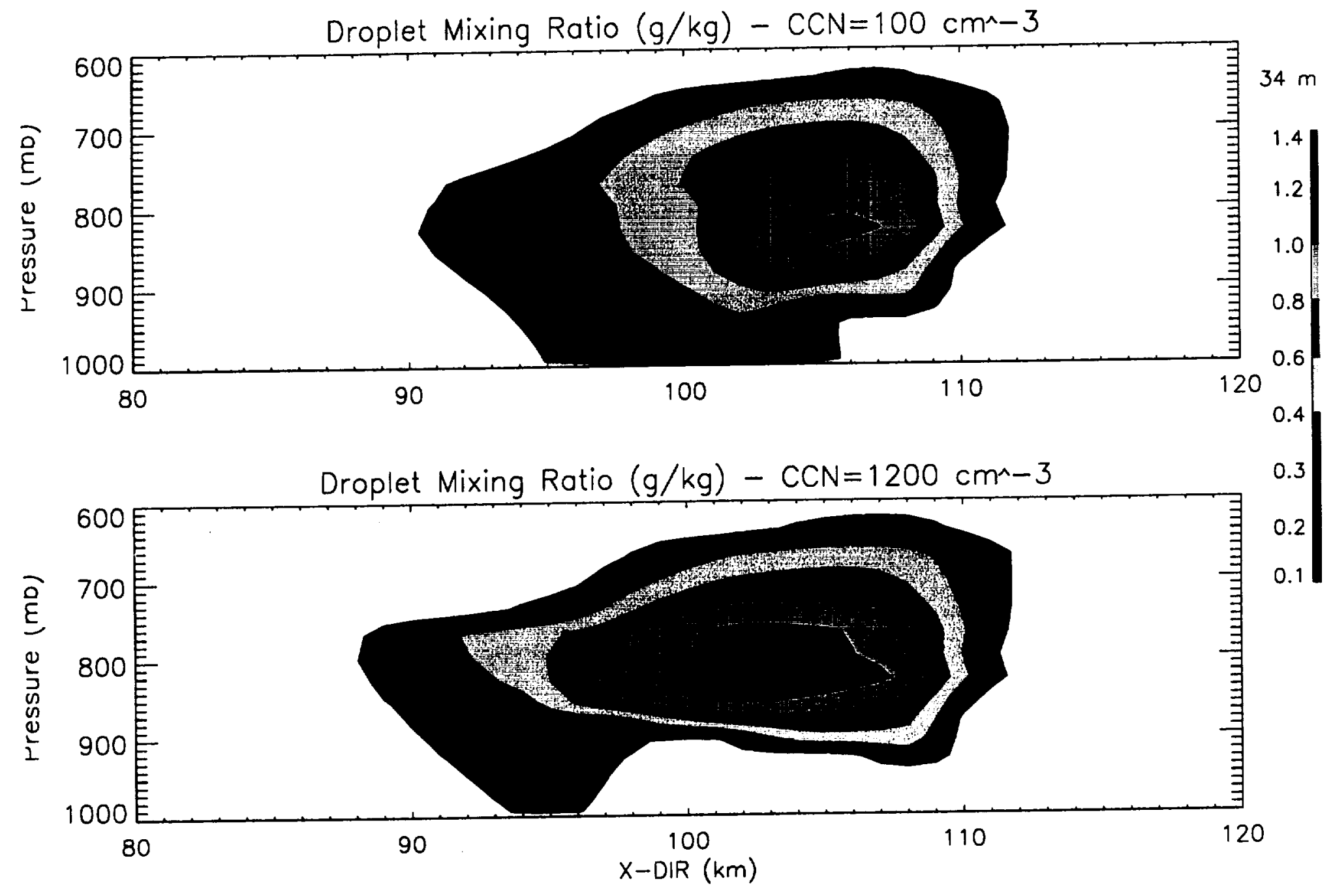

Fig. 10 



Fig. 11 




Fig. 12 


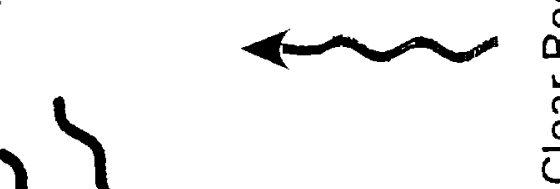

(2) ธั่

$\frac{\Phi}{0}$

$\frac{0}{1}$



을

응

U웡

용

क为要这

व के

क 5

$\frac{\Phi}{0}=\frac{4}{0}$ 


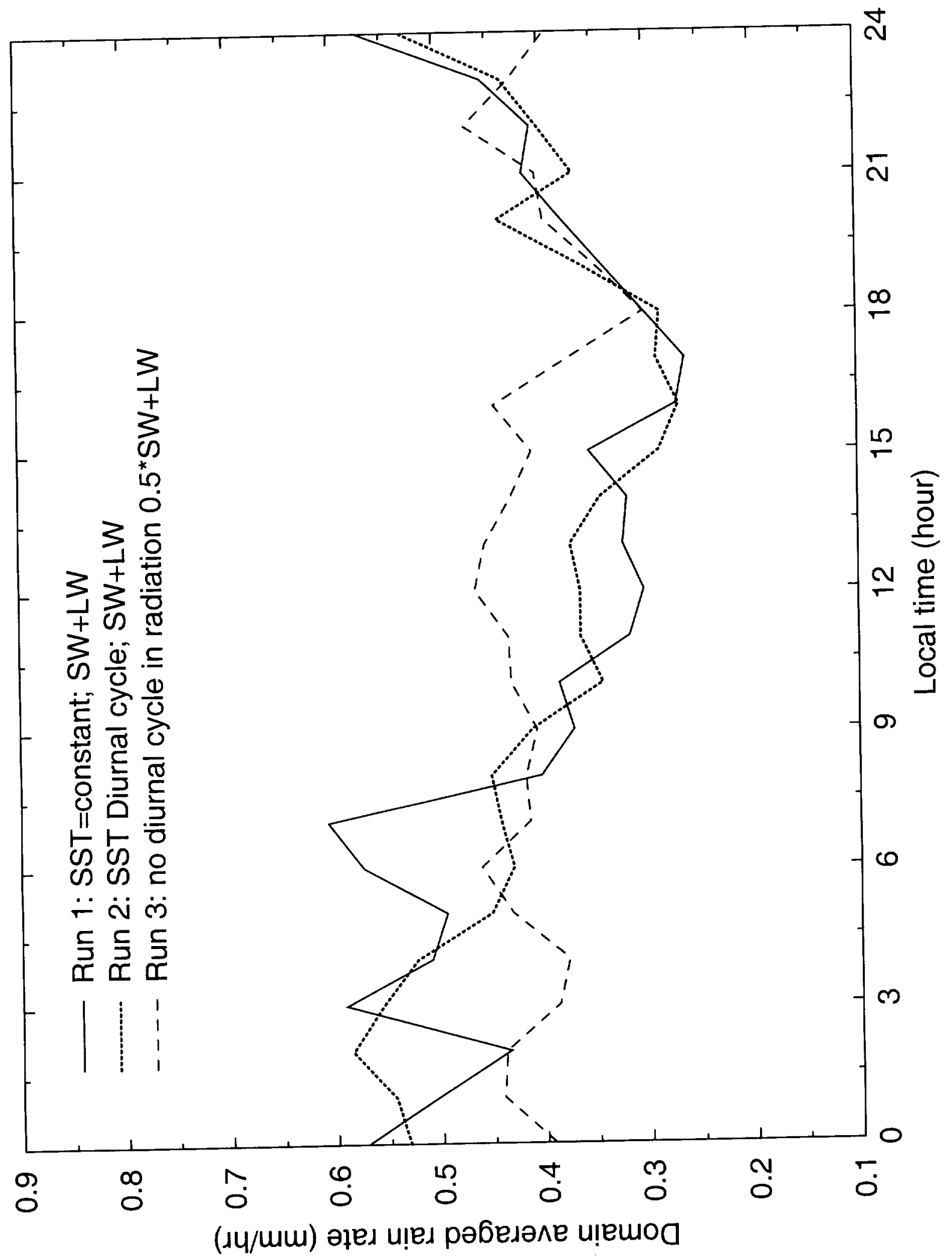




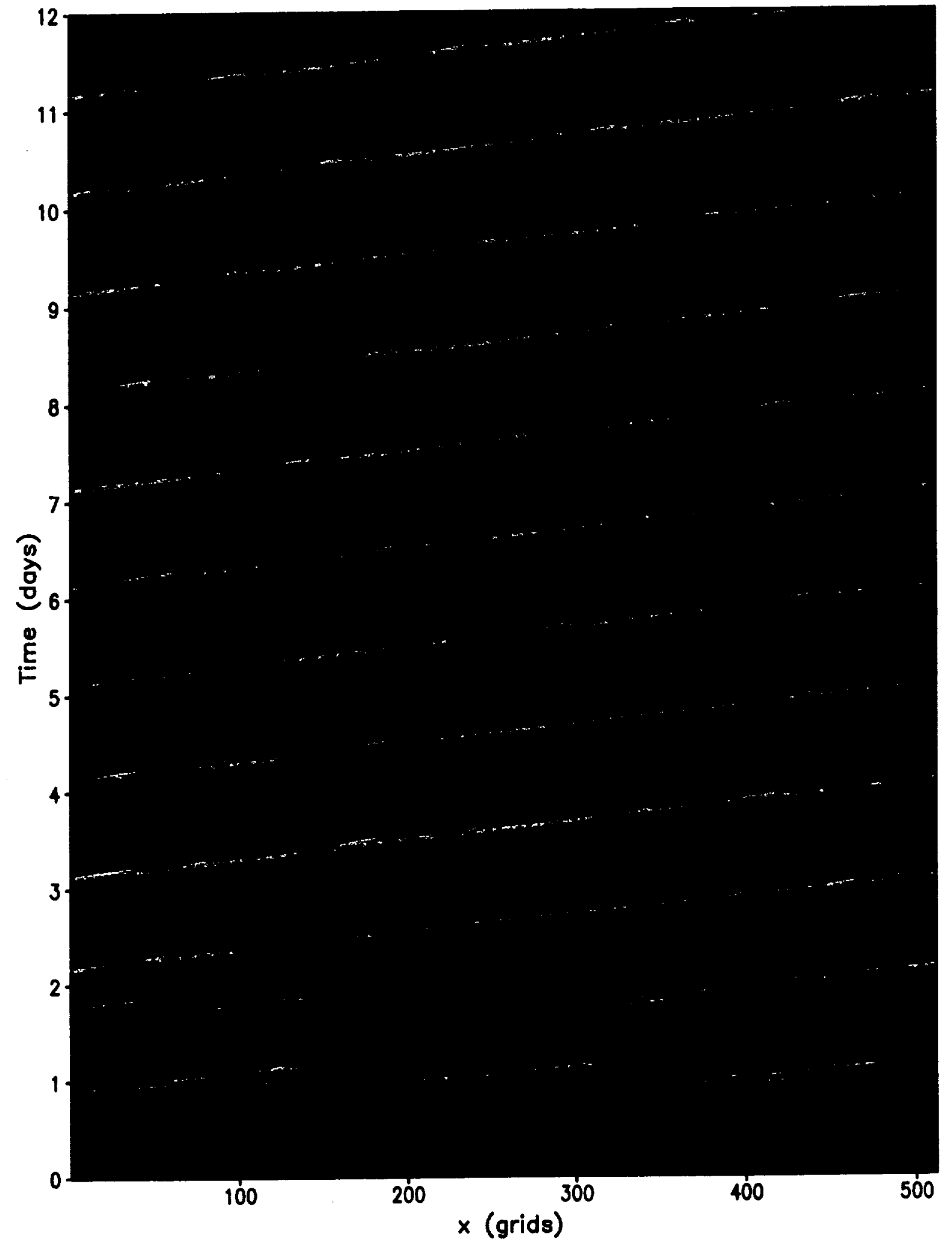

Time-space distribution of rain rate $(\mathrm{mm} / \mathrm{hr})$

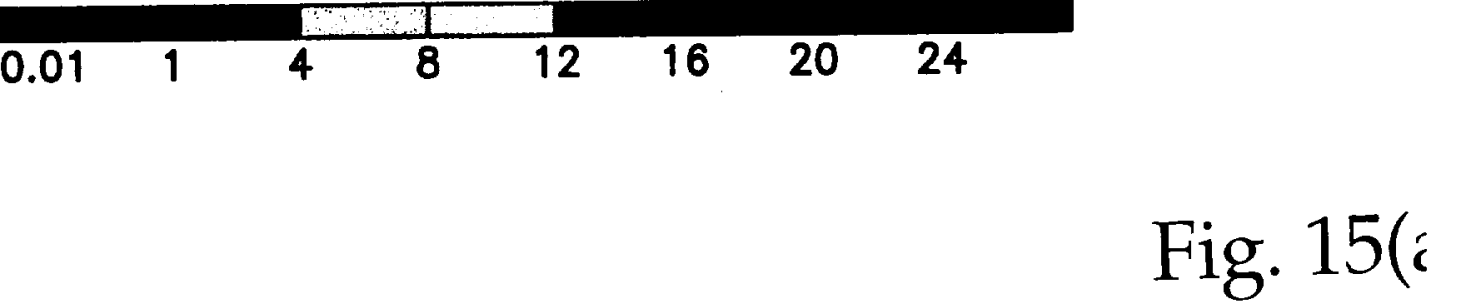

Fig. 15( 


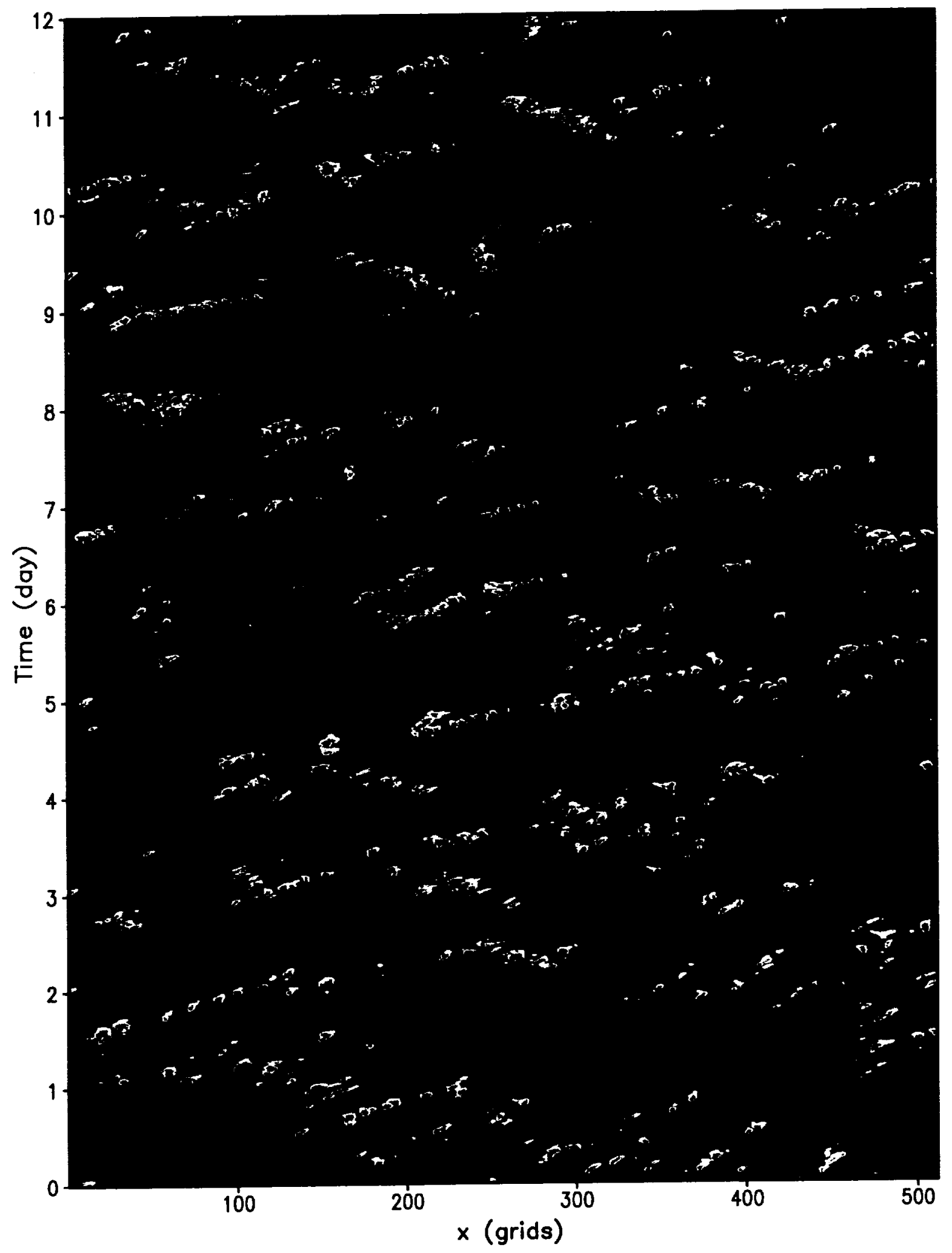

Time-space distribution of rain rate $(\mathrm{mm} / \mathrm{hr})$

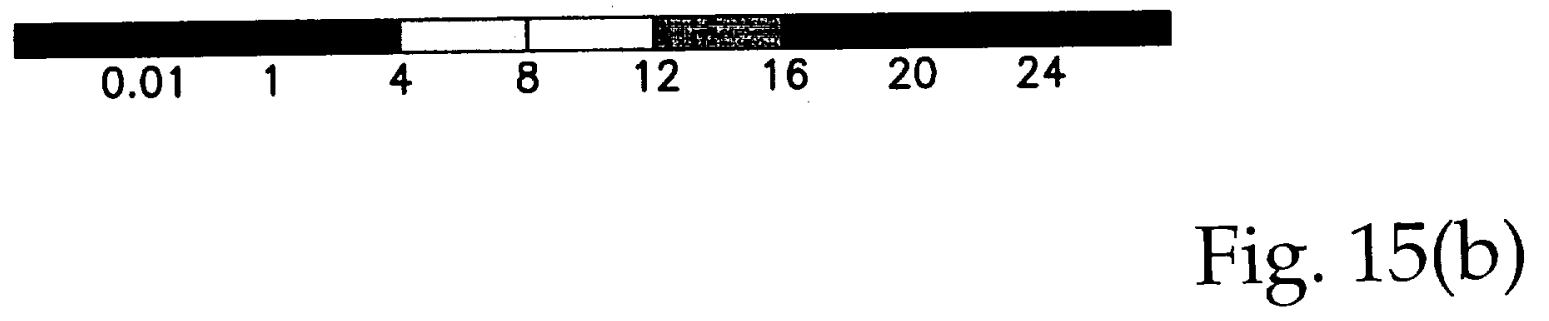






$\infty$




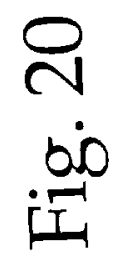

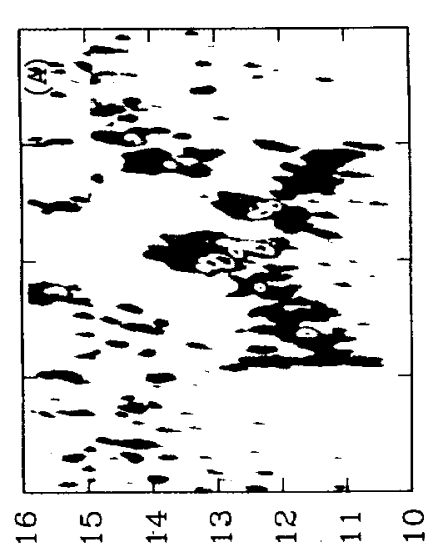

(गप) उWIL


(шy) ЈHפIaH



$\stackrel{\infty}{N}$
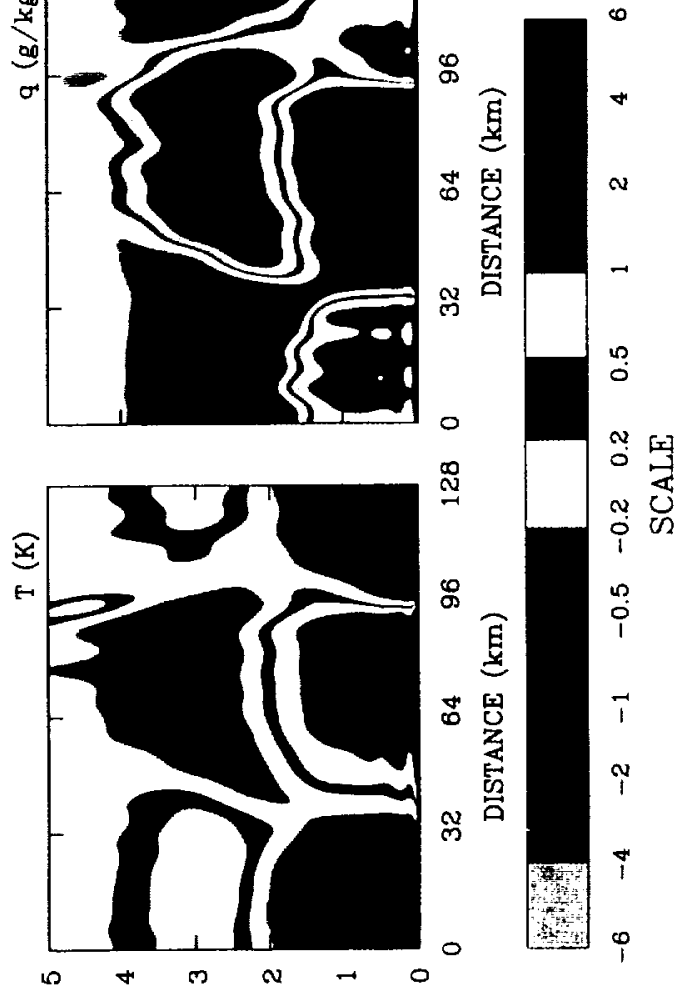

(urr) LHDIaH

$\underset{i \infty}{i=1}$ 




Fig. 21 


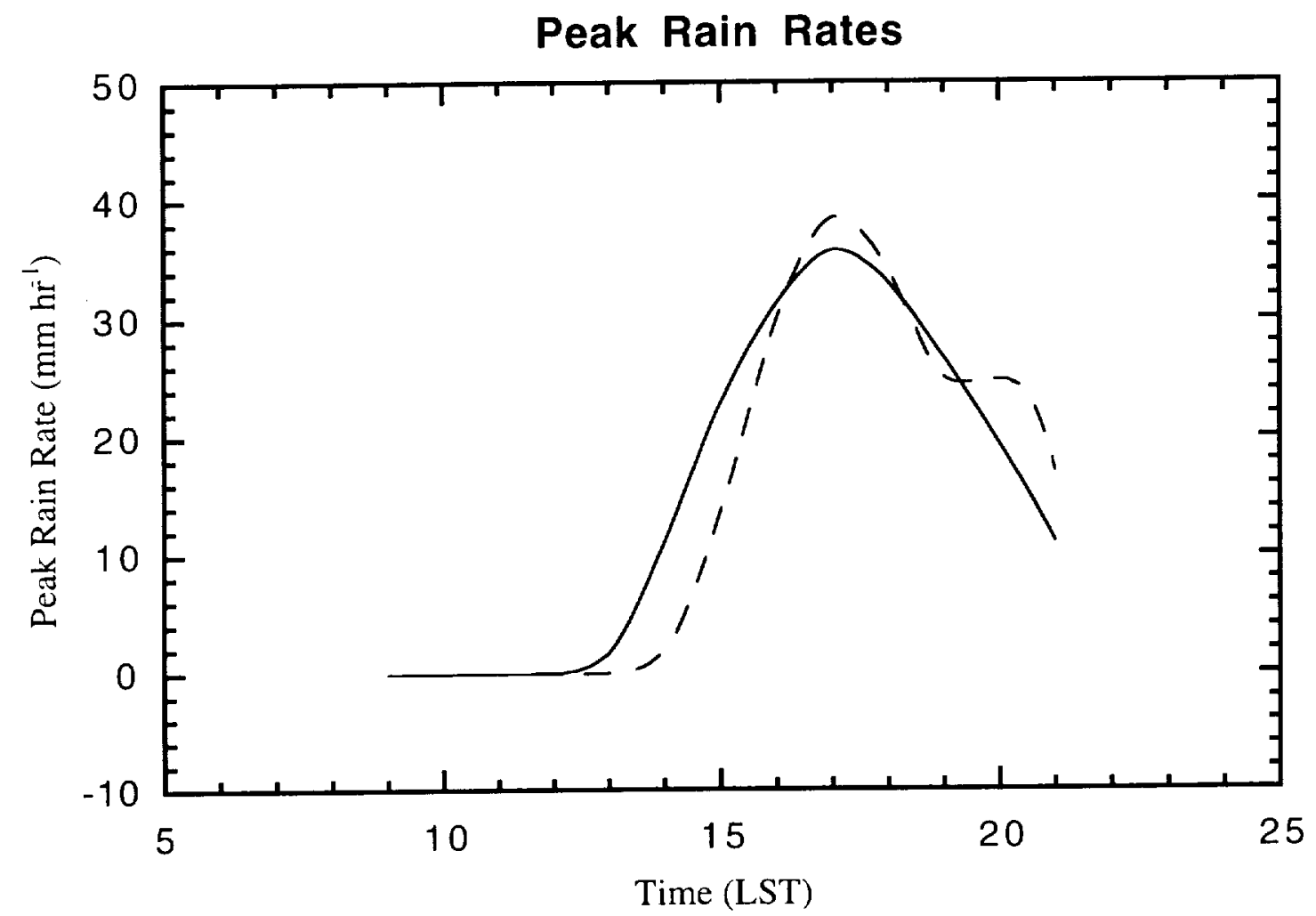

Fig. 22 


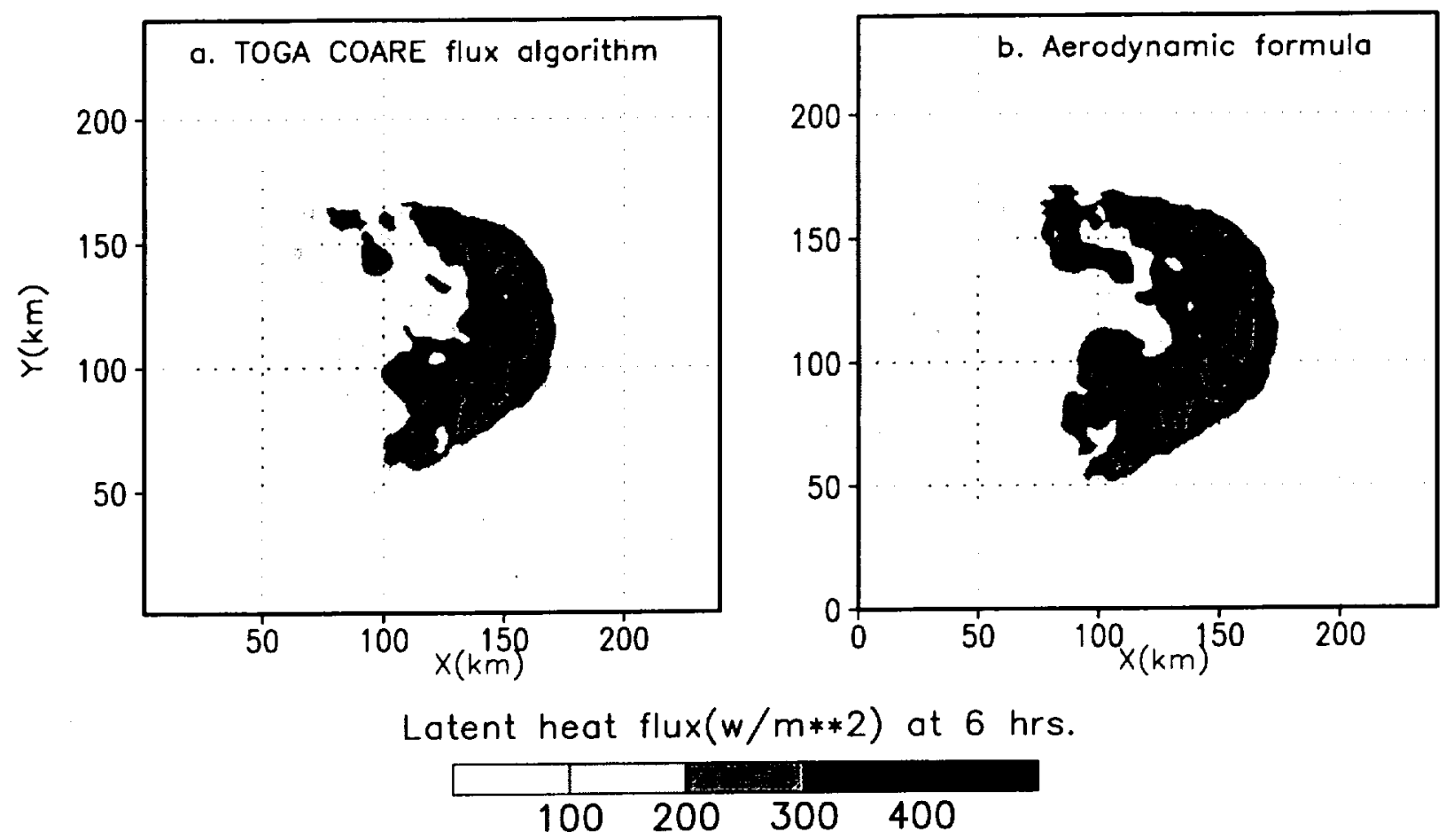

Fig. 23 

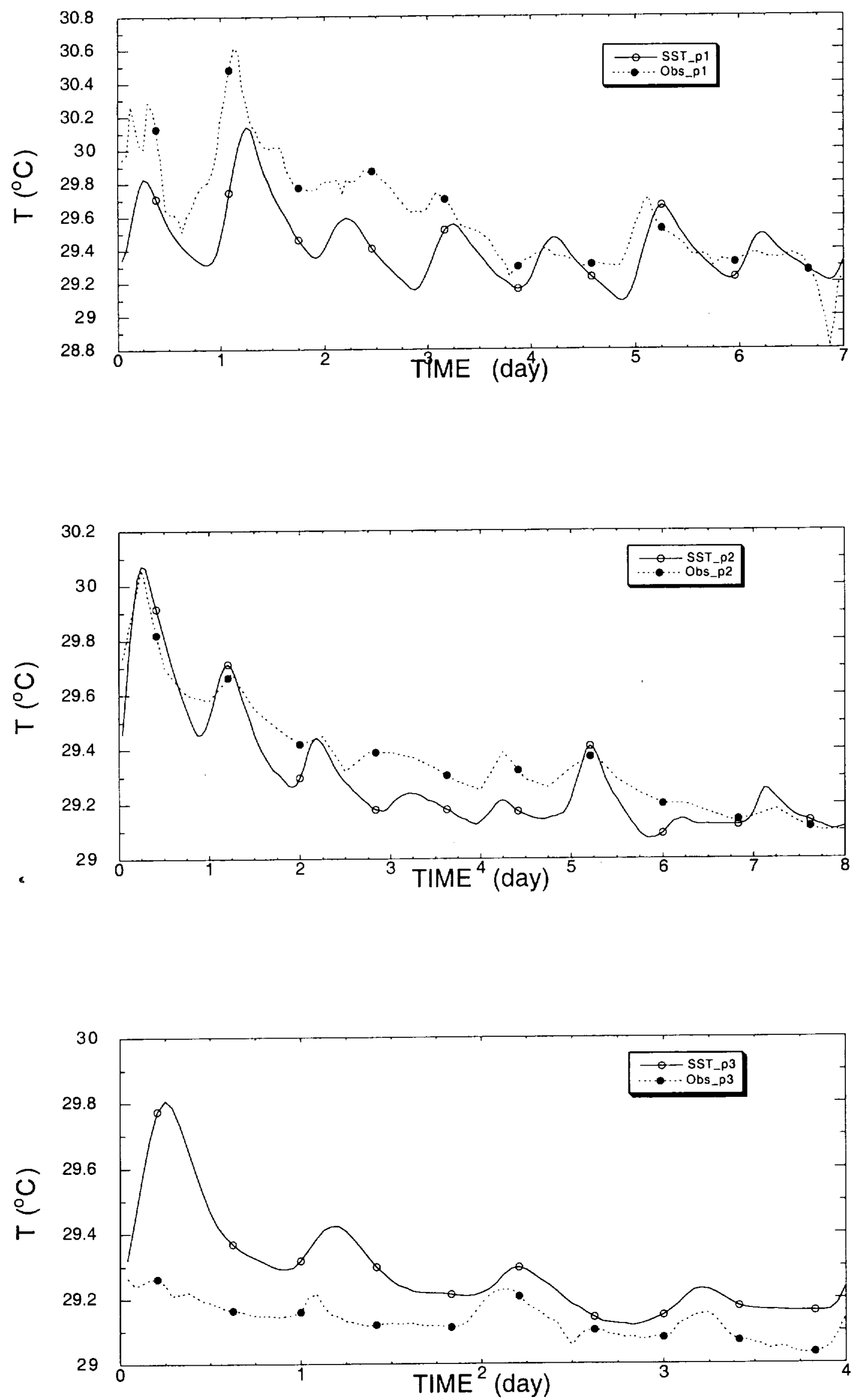

Fig. 24 

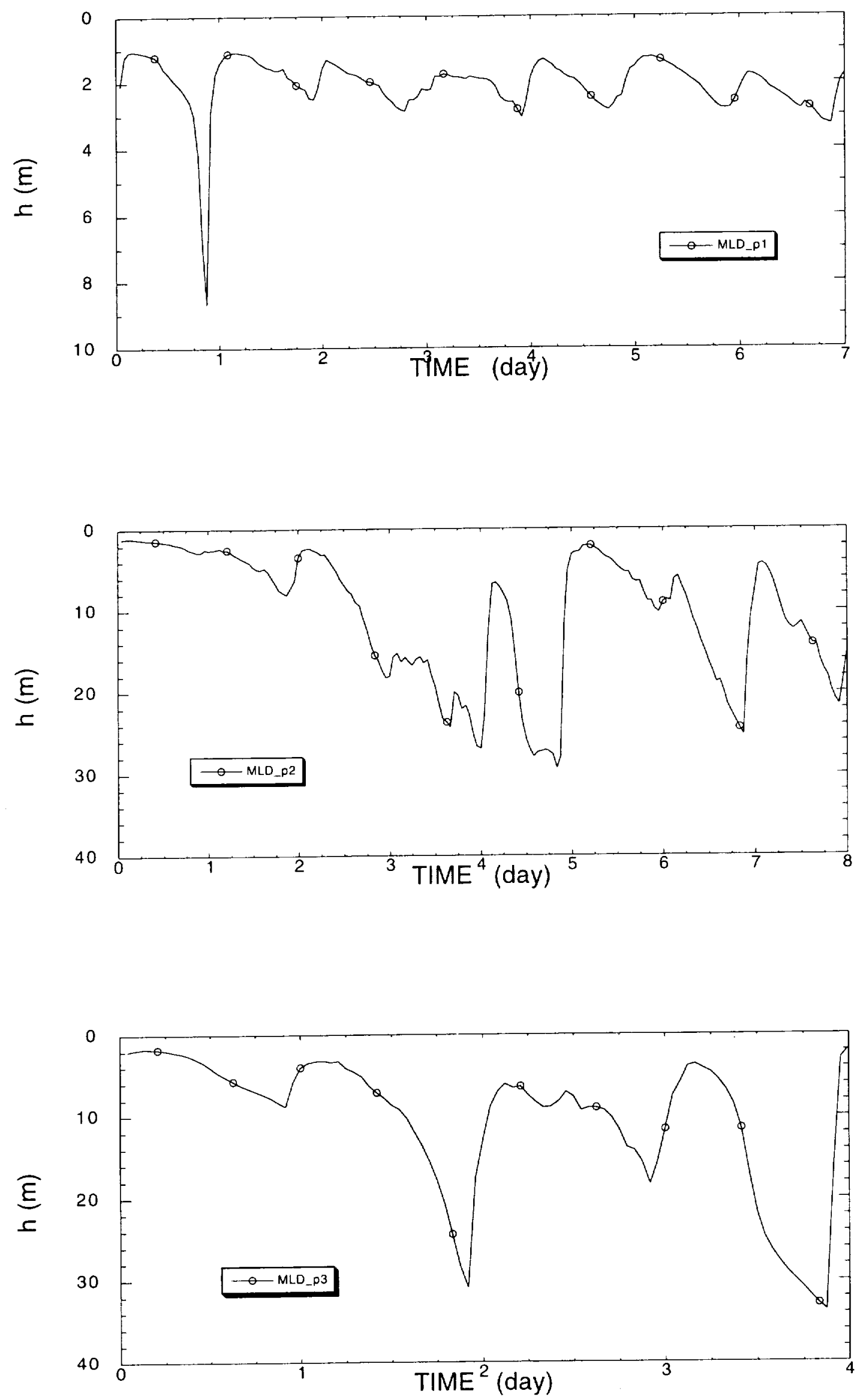

Fig. 25 



Fig. 26 


\begin{tabular}{|c|c|c|c|}
\hline Topics & $\begin{array}{c}\text { Model } \\
\text { Characteristics }\end{array}$ & Major Results & References \\
\hline $\begin{array}{c}\text { Cloud-Cloud } \\
\text { Interactions and } \\
\text { Mergers } \\
\end{array}$ & $\begin{array}{c}2 \mathrm{D} / 3 \mathrm{D} \\
\text { Warm rain }\end{array}$ & $\begin{array}{c}\text { Cloud downdraft and its associated } \\
\text { cold outflow play major role in cloud } \\
\text { merger }\end{array}$ & $\begin{array}{c}\text { Tao and Simpson } \\
(1984,1989 a)\end{array}$ \\
\hline$Q_{1}$ and $Q_{2}$ Budgets & $\begin{array}{c}2 \mathrm{D} / 3 \mathrm{D} \\
\text { Warm rain and } \\
\text { Ice Processes }\end{array}$ & $\begin{array}{l}\text { Importance of evaporative cooling in } \\
\qquad \mathrm{Q}_{1} \text { budget } \\
\text { Importance of vertical transport of } \\
\text { moisture by convection in } \mathrm{Q}_{2} \text { budget }\end{array}$ & $\begin{array}{l}\text { Tao (1978), Soong and } \\
\text { Tao (1980), Soong and } \\
\text { Tao (1986), Tao and } \\
\text { Simpson (1989b), Tao } \\
\text { et al. (1991, 1993a, } \\
\text { 1996), Johnson et al } \\
\text { (2001) }\end{array}$ \\
\hline $\begin{array}{c}\text { Cloud } \\
\text { Characteristics }\end{array}$ & $\begin{array}{l}2 \mathrm{D} / 3 \mathrm{D} \\
\text { Warm rain }\end{array}$ & $\begin{array}{l}\text { Active convective updrafts cover } \\
\text { small area but major contributors in } \\
\text { mass, } Q_{1} \text { and } Q_{2} \text { budgets. } \\
\text { Excellent agreement with aircraft } \\
\text { measurements. }\end{array}$ & $\begin{array}{l}\text { Tao and Soong (1986), } \\
\text { Tao et al. (1987) }\end{array}$ \\
\hline $\begin{array}{l}\text { Convective } \\
\text { Momentum } \\
\text { Transport } \\
\end{array}$ & $\begin{array}{c}\text { 2D/3D } \\
\text { Smaller Domain } \\
\text { in 3D } \\
\end{array}$ & $\begin{array}{c}\text { Identify the role of horizontal } \\
\text { pressure gradient force on up-gradient } \\
\text { transport of momentum. }\end{array}$ & $\begin{array}{l}\text { Soong and Tao (1984), } \\
\text { Tao and Soong (1986), } \\
\text { Tao et al. (1995) } \\
\end{array}$ \\
\hline Ice Processes & $2 \mathrm{D} / 3 \mathrm{D}$ & $\begin{array}{l}\text { The importance of ice processes for } \\
\text { stratiform rain formation and its } \\
\text { associated mass, } Q_{1} \text { and } Q_{2} \text { budgets. }\end{array}$ & $\begin{array}{c}\text { Tao and Simpson } \\
\text { (1989), McCumber et } \\
\text { al. (1991), Tao et al. } \\
\text { (1993a), Ferrier et al. } \\
\text { (1995) }\end{array}$ \\
\hline $\begin{array}{l}\text { Convective and } \\
\text { Stratiform } \\
\text { Interactions }\end{array}$ & $2 \mathrm{D}$ & $\begin{array}{c}\text { The horizontal transport of } \\
\text { hydrometeors and water vapor from } \\
\text { convective towers to stratiform region } \\
\text { are quantified. }\end{array}$ & $\begin{array}{c}\text { Tao et al. (1993a), Sui } \\
\text { et al. (1994), Tao } \\
\text { (1995), Lang et al. } \\
\text { (2001) }\end{array}$ \\
\hline $\begin{array}{l}\text { Cloud Radiation } \\
\text { Interactions } \\
\& \text { diurnal } \\
\text { variation of } \\
\text { precipitation }\end{array}$ & $\begin{array}{l}\text { 2D (short and } \\
\text { long term } \\
\text { integration) }\end{array}$ & $\begin{array}{l}\text { Longwave cooling can enhance } \\
\text { precipitation significantly for } \\
\text { tropical cloud systems, but only } \\
\text { slightly for midlatitude systems. } \\
\\
\text { Modulation in relative humidity by } \\
\text { radiative processes is major reason for } \\
\text { diurnal variation of precipitation. }\end{array}$ & $\begin{array}{l}\text { Tao et al. (1993a), } \\
\text { Tao et al. (1996), Sui } \\
\text { et al. }(1998)\end{array}$ \\
\hline $\begin{array}{l}\text { Cloud Chemistry } \\
\text { Interactions }\end{array}$ & $2 \mathrm{D} / 3 \mathrm{D}$ & $\begin{array}{c}\text { Significant redistribution of trace } \\
\text { gases by convection. Enhancement of } \\
\mathrm{O}_{3} \text { production related to deep } \\
\text { convection in tropics. }\end{array}$ & $\begin{array}{c}\text { Thompson et al (1997 } \\
\text { - a review) }\end{array}$ \\
\hline $\begin{array}{c}\text { Air-Sea } \\
\text { Interactions }\end{array}$ & $2 \mathrm{D} / 3 \mathrm{D}$ & $\begin{array}{c}\text { TOGA COARE flux algorithm } \\
\text { performs well compared with } \\
\text { observation, better than other flux } \\
\text { algorithms. } \\
\text { Surface fluxes are important for } \\
\text { precipitation processes and maintain } \\
\text { CAPE and boundary layer structure. }\end{array}$ & $\begin{array}{l}\text { Wang et al. (1996, } \\
\text { 2001) }\end{array}$ \\
\hline $\begin{array}{c}\text { Precipitation } \\
\text { Efficiency (PE) }\end{array}$ & $2 \mathrm{D}$ & $\begin{array}{l}\text { Examined different definitions of PE. } \\
\text { Identify several important } \\
\text { atmospheric parameters for better PE. }\end{array}$ & Ferrier et al. (1996) \\
\hline
\end{tabular}




\begin{tabular}{|c|c|c|c|}
\hline Land Processes & $2 \mathrm{D} / 3 \mathrm{D}$ & $\begin{array}{l}\text { Importance of mesoscale circulation } \\
\text { induced by soil gradient on } \\
\text { precipitation. Identify the } \\
\text { atmospheric parameters for } \\
\text { triggering convection. }\end{array}$ & $\begin{array}{l}\text { Lynn et al. (1998, } \\
\text { 2001), Lynn and Tao } \\
\text { (2001), Baker et al. } \\
\text { (2001) }\end{array}$ \\
\hline $\begin{array}{l}\text { Idealized Climate } \\
\text { Variations in } \\
\text { Tropics }\end{array}$ & $2 \mathrm{D}$ & $\begin{array}{l}\text { Examined several important } \\
\text { hypotheses associated with climate } \\
\text { variation and climate warming. } \\
\text { Identified physical processes that } \\
\text { cause two different statistical } \\
\text { equilibrium states (warm/humid and } \\
\text { cold/dry) in idealized climates. }\end{array}$ & $\begin{array}{l}\text { Sui et al }(1994), \text { Lau } \\
\text { et al }(1993,1994) \\
\text { Tao et al. (1999, } \\
\text { 2001a), Shie et al. } \\
(2001)\end{array}$ \\
\hline $\begin{array}{c}\text { TRMM Rainfall } \\
\text { Retrieval }\end{array}$ & $3 \mathrm{D}$ & $\begin{array}{l}\text { Improved the performance of TRMM } \\
\text { rainfall retrieval algorithms by } \\
\text { providing realistic cloud profiles. }\end{array}$ & $\begin{array}{c}\text { Simpson et al. (1996- } \\
\text { a review) }\end{array}$ \\
\hline $\begin{array}{l}\text { Latent Heating } \\
\text { Profile Retrieval }\end{array}$ & $2 \mathrm{D}$ & $\begin{array}{l}\text { Developed algorithms for retrieving } \\
\text { four dimensional vertical structure of } \\
\text { latent heating profiles over global } \\
\text { tropics, }\end{array}$ & $\begin{array}{c}\text { Tao et al. }(1990, \\
\text { 1993b, 2000, 2001b) }\end{array}$ \\
\hline
\end{tabular}


Goddard Microphysics Processes (Schemes)

\begin{tabular}{|c|c|c|}
\hline & Characteristics & References \\
\hline Warm Rain & $\mathrm{qc}, \mathrm{qr}$ & $\begin{array}{c}\text { Kessler (1969), Soong and Ogura } \\
\text { (1973) }\end{array}$ \\
\hline 2 Ice & $q c, q r, q i, q g$ & $\begin{array}{c}\text { Cotton et al (1982), Chen (1983), } \\
\text { McCumber et al (1991) }\end{array}$ \\
\hline 3Ice - 1 & qc, qr, qi, qs, qh & $\begin{array}{c}\text { Lin et al (1983), Tao and Simpson } \\
(1989,1993)\end{array}$ \\
\hline 3Ice - 2 & $q c, q r, q i, q s, q g$ & $\begin{array}{l}\text { Rutledge and Hobbs (1984), Tao and } \\
\text { Simpson }(1989,1993)\end{array}$ \\
\hline 3Ice -3 & $q c, q r, q i, q s, q h$ & $\begin{array}{l}\text { Lin } e \text { al (1983), Rutledge and Hobbs } \\
\text { (1984), Ferrier at al (1995) }\end{array}$ \\
\hline 3Ice -4 & $q c, q r, q i, q s, q g$ or $q h$ & Lin et al (1983), Scott et al (2001) \\
\hline 3 Ice -5 & Saturation Technique & Taoet al (1989), Tao et al (2001) \\
\hline 4Ice - 1 & $\begin{array}{l}\mathrm{qc}, \mathrm{qr}, \mathrm{qi}, \mathrm{qs}, \mathrm{qg}, \mathrm{qh} \\
\mathrm{Ni}, \mathrm{Ns}, \mathrm{Ng}, \mathrm{Nh}\end{array}$ & Ferrier (1994) \\
\hline 4Ice - 2 & $\begin{array}{l}\mathrm{qc}, \mathrm{qr}, \mathrm{qi}, \mathrm{qs}, \mathrm{qg}, \mathrm{qh} \\
\mathrm{Ni}, \mathrm{Ns}, \mathrm{Ng}, \mathrm{Nh}\end{array}$ & Taoet al (2001) \\
\hline Spectral-Bin & $\begin{array}{c}43 \text { bins for } 6 \text { types ice, liquid } \\
\text { water and cloud } \\
\text { condensation nuclei }\end{array}$ & $\begin{array}{c}\text { Khain and Sednev (1996) and Khain } \\
\text { et al. (1998). }\end{array}$ \\
\hline
\end{tabular}




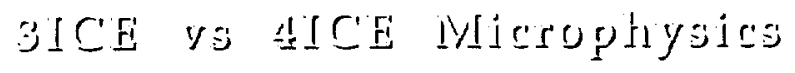

\begin{tabular}{|c|c|c|}
\hline & 3ICE & 4ICE \\
\hline Hydrometeors & $\begin{array}{c}\text { Ice, Snow and Graupel or } \\
\text { Hail }\end{array}$ & $\begin{array}{c}\text { Ice, Snow, Graupel and } \\
\text { Hail }\end{array}$ \\
\hline $\begin{array}{c}\text { Processes } \\
\text { Involved }\end{array}$ & 35 & 90 \\
\hline $\begin{array}{c}\text { Number } \\
\text { Concentration }\end{array}$ & Prescribed & $\begin{array}{c}\text { Predicted (Ni, Ns, Ns and } \\
\text { Ng) }\end{array}$ \\
\hline Wet Ice & None & Included \\
\hline Tuning & $\begin{array}{c}\text { Needed for different } \\
\text { environment }\end{array}$ & Minimal \\
\hline Ice Crystal & No Fall Speed & Fall Speed \\
\hline Rain DSD & Exponential & Gamma - Realistic \\
\hline
\end{tabular}




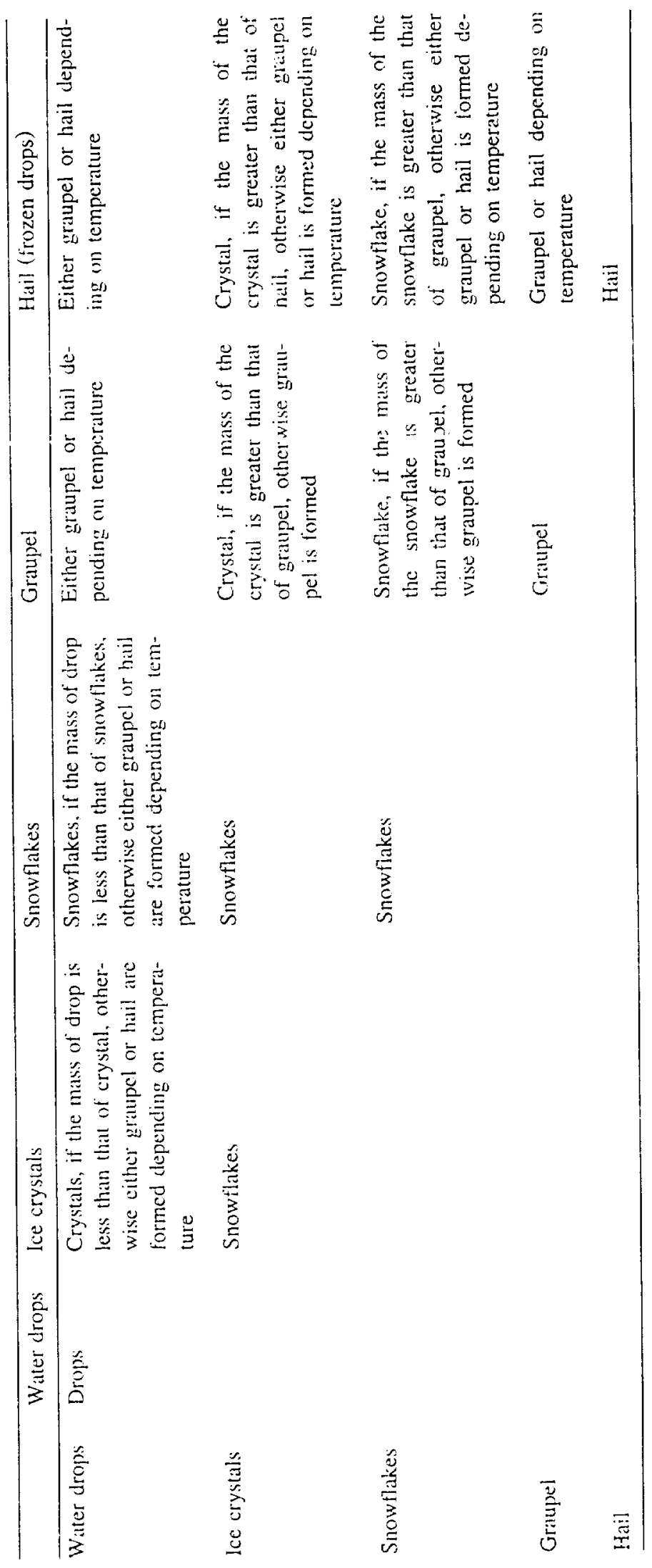

$\frac{\pi}{0}$ 
$\frac{0}{0}$
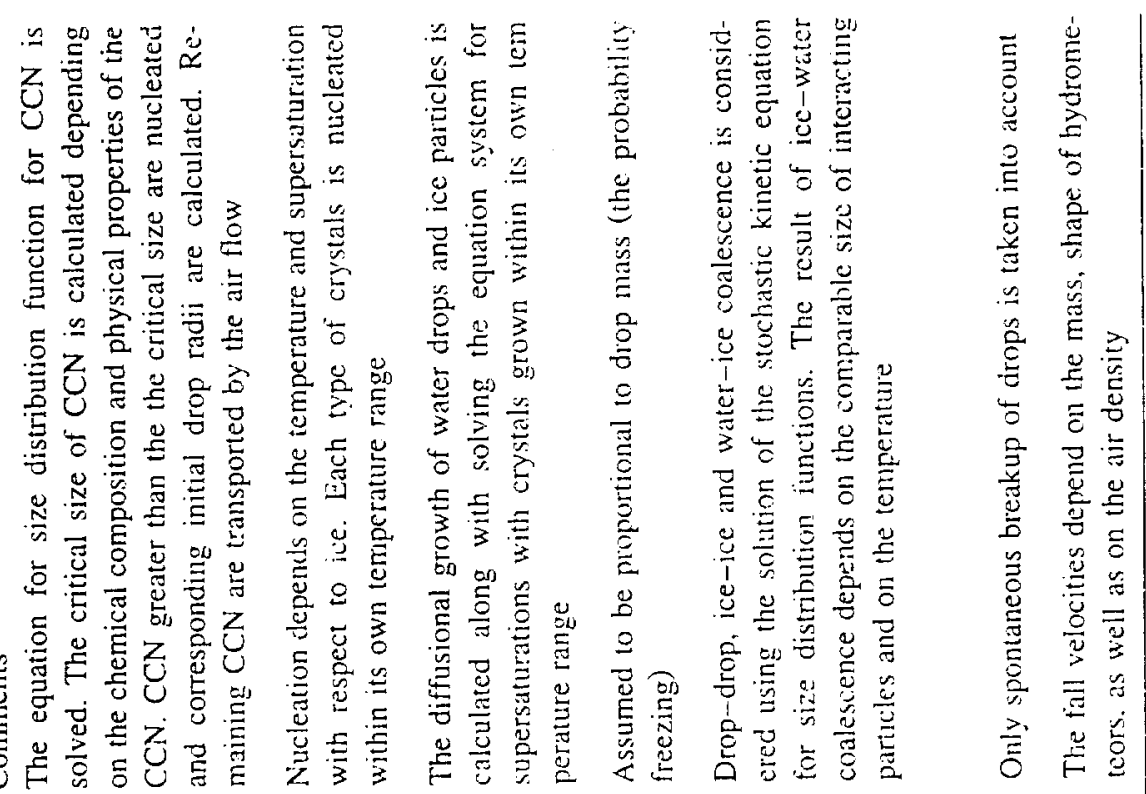

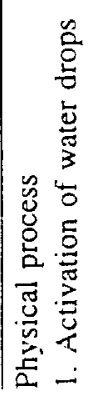
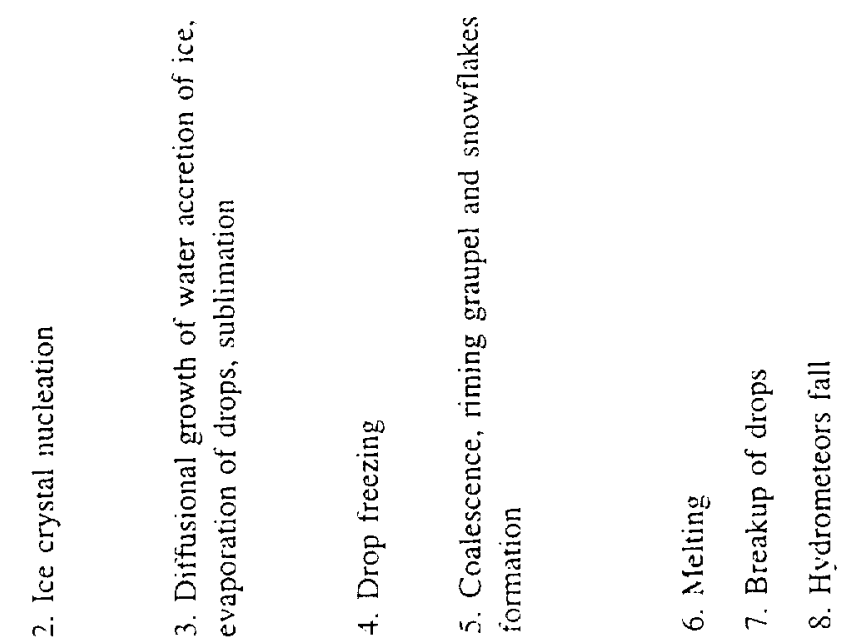

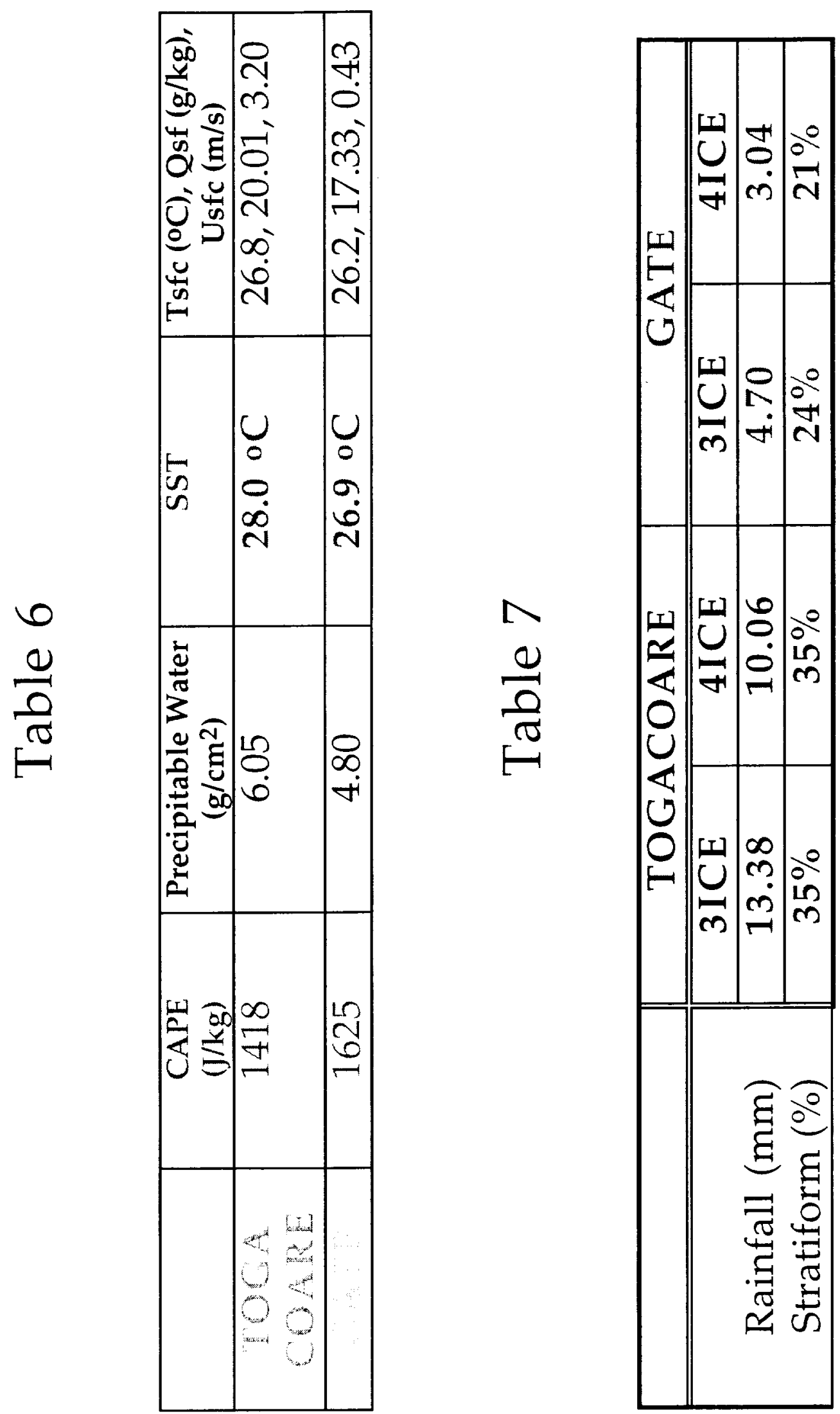

